\title{
$\beta$-catenin Confers Resistance to PI3K and AKT inhibitors and Subverts FOXO3a to Promote Metastasis in Colon Cancer
}

Stephan P. Tenbaum ${ }^{1 \S}$, Paloma Ordóñez-Morán ${ }^{2 \S \#}$, Isabel Puig ${ }^{1 \S}$, Irene Chicote ${ }^{1}$, Oriol Arqués ${ }^{1}$, Stefania Landolfi ${ }^{3}$, Yolanda Fernández ${ }^{4}$, José Raúl Herance ${ }^{5}$, Juan D. Gispert ${ }^{5}$, Leire Mendizabal ${ }^{6}$, Susana Aguilar ${ }^{7}$, Santiago Ramón y Cajal ${ }^{3}$, Simó Schwartz $\mathrm{Jr}^{4}$, Ana Vivancos $^{6}$, Eloy Espín ${ }^{8}$, Santiago Rojas ${ }^{5}$, José Baselga ${ }^{9}$, Josep Tabernero ${ }^{10}$, Alberto Muñoz ${ }^{2}$, Héctor G. Palmer ${ }^{1 *}$

${ }^{1}$ Vall d'Hebrón Institut d'Oncología (VHIO). Stem Cells and Cancer Laboratory. Barcelona, Spain.

${ }^{2}$ Instituto de Investigaciones Biomédicas "Alberto Sols", Consejo Superior de Investigaciones Científicas-Universidad Autónoma de Madrid, Madrid, Spain.

3 Department of Pathology, Hospital Universitari Vall d'Hebrón, Universitat Autònoma de Barcelona, Barcelona, Spain.

${ }^{4}$ Group of Drug Delivery and Targeting, CIBBIM-Nanomedicine and Networking Biomedical Research Center on Bioengineering, Biomaterials and Nanomedicine (CIBER-BBN), Hospital Universitari Vall d'Hebrón, Institut de Recerca Vall d'Hebrón, Universitat Autònoma de Barcelona, Barcelona, Spain.

5 Parc de Recerca Biomèdica de Barcelona (PRBB), Centre d'Imatge Molecular (CRC) Corporació Sanitària, Barcelona, Spain.

${ }^{6}$ Vall d'Hebrón Institut d'Oncología (VHIO). Genomics Cancer Group. Barcelona, Spain.

${ }^{7}$ Centre for Respiratory Research, Rayne Institute, University College London, London, United Kingdom, Hematopoietic Stem Cell Laboratory, London Research Institute, Cancer Research UK, London, United Kingdom.

${ }^{8}$ General Surgery Service, Hospital Universitari Vall d'Hebrón, Barcelona, Spain.

${ }^{9}$ Massachusetts General Hospital Cancer Center, Harvard Medical School, Charlestown, USA; Howard Hughes Medical Institute, Chevy Chase, USA.

${ }^{10}$ Medical Oncology Department, Hospital Universitari Vall d'Hebrón, Barcelona, Spain.

\# Swiss Institute for Experimental Cancer Research, École Polytechnique Fédérale de Lausanne, Lausanne, Switzerland.

*Corresponding author: hgpalmer@vhio.net

Telephone: +34 932746000 ext: 4925 FAX: +34 932746708

$\S$ S.P.T., P.O-M and I.P. contributed equally to this work.

Running title: FOXO3a and $\beta$-catenin cooperate to induce colon cancer metastasis 


\section{ABSTRACT}

Wnt/ $\beta$-catenin and PI3K/AKT pathways play a central role in cancer. We describe the function of their corresponding transcriptional effectors $-\beta$-catenin and $\mathrm{FOXO} 3 \mathrm{a}-$ in colon cancer progression. Their simultaneous nuclear accumulation and activation promotes cell scattering and metastasis, by regulating a defined set of target genes. Unexpectedly, the anti-tumoral AKT inhibitor API-2 promotes nuclear FOXO3a accumulation and metastasis of cells with high nuclear $\beta$-catenin. $\beta$-catenin confers resistance to FOXO3a-mediated apoptosis induced by $\mathrm{PI} 3 \mathrm{~K}$ and AKT inhibitors in patient-derived primary cultures and in corresponding xenograft tumors in mice. This resistance is reverted by $\mathrm{Wnt} / \mathrm{\beta}$-catenin signaling inhibitor XAV-939. FOXO3a does not behave as a tumor suppressor but rather as a metastasis inductor activated by PI3K or AKT inhibitory drugs when acting in concert with $\beta$-catenin. We show that it is possible to evaluate $\beta$ catenin status and the response of patient-derived cells to these target-directed drugs before deciding on treatment. We also consider that this evaluation could be essential to the provision of a safer and more effective personalized treatment. 


\section{INTRODUCTION}

Colon cancer is a leading cause of death worldwide ${ }^{1}$. Although surgical resection combined with adjuvant therapy is efficient at early stages of the disease, subsequent relapse and metastasis are frequent. At these advanced stages, conventional therapies are ineffective ${ }^{1-3}$. It is important to identify novel predictive biomarkers and to provide tools to facilitate treatment decisions. A better understanding of the molecular mechanisms responsible for drug-resistance and metastasis is crucial to these aims.

Abnormal activation of the Wnt/ß-catenin pathway by mutations in Adenomatous Polyposis Coli $(A P C), A X I N 2$ or $\beta$-catenin (CTNNB1) is responsible for the initiation of almost all colon cancers $^{4,5}$. Wht signal leads to the disassembly of a destruction complex formed by APC, AXIN and GSK3beta. This complex can no longer target $\beta$-catenin for degradation. As a result, $\beta$ catenin accumulates in the cell, enters the nucleus, binds the TCF/LEF transcription factors and induces expression of Wnt target genes ${ }^{6}$. A significant number of these genes play key roles in tumour progression by inducing cell proliferation, while fewer genes drive cell motility and migration $^{7,8}$.

The pleiotropic effects of the Wnt pathway are, however, so broad and varied that they cannot be explained through this molecular mechanism alone. We and others have reported that binding of $\beta$-catenin to different transcription factors enhances the expression of alternative sets of target genes directing cell-fate during development, tissue homeostasis and cancer ${ }^{9-13}$. FOXO3a is one of these transcription factors, for which $\beta$-catenin acts as a transcriptional coactivator, enhancing the expression of genes involved in longevity and oxidative stress ${ }^{14}$. However, to our knowledge the possible physiological relevance of the crosstalk between FOXO3a and $\beta$-catenin in cancer has not been addressed.

FOXO proteins control multiple processes in eukaryotic organisms by regulating the expression of specific sets of genes involved in stem-cell maintenance, stress resistance, longevity, differentiation, metabolism or tumor suppression ${ }^{15-19}$. In cancer, FOXO transcription factors are considered tumor suppressors because they induce cell-cycle arrest and

apoptosis $^{16,20-23}$. However, prolonged activation of FOXO proteins confers drug-resistance in 
cancer cells by promoting the expression of genes responsible for antioxidant defence, DNA repair or drug efflux ${ }^{20,22}$. The molecular mechanisms underlying such dual activity, cell death versus resistance, have not yet been characterized.

The response of FOXO proteins to environmental stimuli is controlled by their subcellular localization $^{16}$. Phosphorylation of FOXO proteins by activated AKT or SGK1 at three specific residues induces their sequestration in the cytoplasm and the consequent inhibition of their capacity to regulate target genes ${ }^{24,25}$. AKT is part of the RAS/PI3K/PTEN/AKT/mTOR oncogenic pathway, which is frequently altered by activating mutations in colon cancer and many others ${ }^{26}$. In this scenario, FOXO proteins are retained in the cytoplasm of cancer cells, which blocks their tumor suppressor activity ${ }^{20}$. Concerted efforts have been made in both academia and industry to identify specific PI3K or AKT inhibitors with which to fight cancer ${ }^{20,27-30}$. The aim is to relocate FOXO proteins back into the nucleus and thus restore their capacity to induce cell-cycle arrest and apoptosis ${ }^{20}$. The anti-tumoral efficacy of some of these compounds has been tested in clinical trials, with promising results ${ }^{27,28}$. In this study we used the PI3K inhibitor NVP-BKM120 and the AKT signaling inhibitor-2 (API-2), also known as Triciribine Phosphate Monohydrate (TCN-PM, VD-0002). Both drugs inhibit cell growth and induce apoptosis in human cancer cells in culture and in tumors growing in mice ${ }^{31,32}$. Phase I and II clinical trials with NVP-BKM120 and API-2 respectively have been conducted in patients with solid metastatic cancers ${ }^{33-35}$.

Considering the role of $\mathrm{Wnt} / \beta$-catenin and PI3K/AKT pathways in tumorigenesis and the interaction of their corresponding transcriptional effectors, FOXO3a and $\beta$-catenin, we decided to study their crosstalk in colon cancer. Unexpectedly, we found that their joint action induced metastasis and that $\beta$-catenin conferred resistance to FOXO-induced apoptosis. PI3K and AKT inhibitors not only failed to induce apoptosis in vitro and in vivo, but they also promoted metastasis when the concentration of nuclear $\beta$-catenin was high in colon-cancer cells. By studying the response of patient-derived colon cancer initiating cells to such target-directed drugs we highlight the clinical relevance of our findings. 
Our results indicate that drugs promoting FOXO tumor suppressor activity can induce metastasis acting in concert with nuclear $\beta$-catenin, by inducing a set of common target genes. We show that it is possible to monitor $\beta$-catenin levels and drug response in patient-derived cell cultures. We also consider this evaluation to be advisable for the provision of a safer and more effective individual treatment. Those patients with high nuclear $\beta$-catenin levels are not expected to benefit from PI3K or AKT inhibitory drugs, but they may do so through the simultaneous inhibition of Wnt/ß-catenin signaling. 


\section{RESULTS}

High nuclear FOXO3a and $\beta$-catenin levels correlate with metastatic tumor stages and shorter survival in colon-cancer patients.

We analyzed the expression of $\mathrm{FOXO} 3 a$ and $\beta$-catenin in series of patients' carcinomas at different stages of colon-cancer progression. Nuclear FOXO3a accumulated alone in nonmalignant adenomas but always colocalized with $\beta$-catenin in the nucleus of tumoral cells in carcinomas or liver metastasis (Fig. 1a-e and Supplementary Fig. 1c). Such colocalization was revealed by plotting the values of nuclear signal for $\mathrm{FOXO} 3 a$ and $\beta$-catenin colocalization against that for nuclear FOXO3a alone (Fig. 1d). We also detected carcinomas with high nuclear $\beta$ catenin but low nuclear FOXO3a signal (Supplementary Fig. 1a,b). The highest nuclear levels of both factors were observed in a subset of primary carcinomas at stages III and IV from patients with metastatic disease (Fig. 1e). Patients with high nuclear FOXO3a and $\beta$-catenin colocalization signal presented on average eight months shorter survival. Median survival was 33.7 months for low and 25.7 months for high FOXO3a and $\beta$-catenin content (HR, 1.724; 95\% Cl, 1.164-2.552) (Fig. 1f). Those patients presenting the $10 \%$ highest colocalization signal did not survive longer than 28 months, whereas at this time point the remaining patients presented $50 \%$ survival. In this case median survival was 28.9 months for low and 21.03 months for high FOXO3a and $\beta$-catenin content (HR, 6.392; 95\% Cl, 2.322-17.6) (Fig. 1g,h). Nuclear FOXO3a on its own also correlated with metastatic stages (Supplementary Fig.1c) and shorter median survival (Low $=32.57$ vs High $=25.37$ months. $\mathrm{HR}, 1.684 ; 95 \% \mathrm{Cl}, 1.137-2.493$ ) (Supplementary Fig. 1e). In contrast, $\beta$-catenin signal alone did not predict metastasis or survival $(\mathrm{HR}, 1.212 ; 95 \% \mathrm{Cl}, 0.8331-1.765)$ (Supplementary Fig. 1d,f).

$\beta$-catenin cooperates with FOXO3a to promote cell scattering and metastasis, conferring resistance to FOXO3a-induced apoptosis.

To study the effect of both transcription factors in colon cancer cells we expressed a

tamoxifen-inducible $(4 \mathrm{OHT})$ AKT-insensitive mutant of FOXO3a (FOXO3a3A-ER $\left.{ }^{\mathrm{TM}}\right)^{36}$ and a 


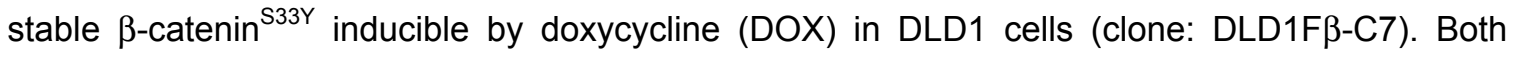
proteins accumulated in the nucleus following treatment, reaching nuclear levels comparable to those caused by $\mathrm{H}_{2} \mathrm{O}_{2}$ (FOXO3a) or present in cancer cell lines such as HCT116 or SW480 with naturally-occurring $\beta$-catenin accumulation (Fig. 2a and Supplementary Fig. 2a-d). 4OHT induced the known FOXO3a target gene CDKN1A (p2 $1^{\mathrm{CIP} 1}$ ) and its protein levels (Fig. $\left.2 \mathrm{~b}, \mathrm{c}\right)^{37}$. Likewise, DOX induced the TCF/ $\beta$-catenin target gene $L E F 1$, whose expression was reduced by $4 \mathrm{OHT}$ (FOXO3a) (Fig. 2b,c) ${ }^{38}$. Simultaneously, nuclear $\beta$-catenin accumulation enhanced the capacity of FOXO3a to induce CDKN1A gene and protein expression (Fig. 2b,c).

As expected ${ }^{39}$, exogenous FOXO3a reduced proliferation accumulating DLD1F $\beta$-C7 cells in G1-phase of the cell cycle. In contrast, $\beta$-catenin promoted proliferation, although the FOXO3a effect was dominant (Fig. 2d and Supplementary Fig. 3a,b). Surprisingly, $\beta$-catenin completely rescued DLD1F $\beta-C 7$ cells from FOXO3a-induced apoptosis (Fig. 2e). Such apoptosis induction and rescue was independent of proliferation since it was preserved in cells arrested in G1 phase upon Mitomycin C pre-treatment (Supplementary Figure 3c-e). These results were confirmed in vivo by subcutaneous injection to nude mice of a pool of DLD1F $\beta$ cells that were all positive for FOXO3a3A-ER, although only $62 \%$ of them expressed $\beta$-catenin ${ }^{\mathrm{S} 33 Y}$-IRES-eGFP (Supplementary Fig. 4a,c,d and Supplementary Fig. 5a,b). This mixed pool of cells recapitulated similar heterogeneity in nuclear $\beta$-catenin levels to that detected in human colon carcinomas (Supplementary Fig. 4b). Tumors thus grew more rapidly in mice treated with DOX but much more slowly in mice treated with $4 \mathrm{OHT}$ compared to controls (Vehicle) (Fig. 2f). Nuclear FOXO3a accumulation was again dominant over $\beta$-catenin activity, and the combined treatment $(4 \mathrm{OHT}+$ DOX) resulted in tumors with similar size at the end of the experiment to those treated with $4 \mathrm{OHT}$ alone. Curiously, tumors with nuclear FOXO3a and $\beta$-catenin (4OHT + DOX) grew faster at the beginning of the experiment than $4 \mathrm{OHT}$-treated tumors, probably due to the protective effect of $\beta$ catenin against an accumulative FOXO3a-induced apoptosis (Fig. 2f). This result reflects that $\beta$ catenin dominates the balance between apoptosis and proliferation over FOXO3a in the context of long-term tumor growth. We again observed that FOXO3a induced apoptosis in DLD1F $\beta$ cells 
but only in the population lacking $\beta$-catenin expression (eGFP-negative cells) both in culture (Supplementary Fig. 4e) and in xenograft tumors (Fig. 2g). Within the tumor tissue this resulted in massive FOXO3a-induced cell death, which was partially rescued upon $\beta$-catenin expression (Supplementary Fig. 5c,d). Detailed histological analysis and quantification showed that nuclear accumulation of FOXO3a and $\beta$-catenin was significantly increased upon $4 \mathrm{OHT}$ or DOX treatment respectively $(P<0.0001)$, although some heterogeneity was observed across tumor tissues (Supplementary Fig. 5f,e).

Cells accumulating high levels of both transcriptional regulators lost their epithelial phenotype in subconfluent cell cultures and in vivo (Fig. 2a, Supplementary Fig. $5 f$ and Supplementary Fig. 6a,b). Since human primary tumors with high FOXO3a and $\beta$-catenin colocalization signal corresponded to patients with local or distant metastasis (Stage III or IV; Fig. $1 \mathrm{e})$, this cell scattering phenotype may reflect a more motile or invasive capacity - both of which are necessary for cancer cells to acquire metastatic potential. FOXO3a accumulation alone initiated a rapid loss of the epithelial phenotype that preceded cell death by apoptosis (Fig. 2a,e and Supplementary Fig. 6a).

We detected relocation of E-cadherin protein from cell-to-cell contacts to cytoplasmic aggregates (Fig. 3a,b and Supplementary Fig. 6e,f) in cells in which the joint action of FOXO3a and $\beta$-catenin induced this scattering phenotype (Supplementary Fig. 6a,b). E-cadherin protein fragments were not detected, which ruled out E-cadherin proteolysis as a mechanism of cell-tocell detachment (Supplementary Fig. 6c). Furthermore, E-cadherin expression was not repressed and Snail1, Zeb1 or Slug levels did not increase (Supplementary Fig. 6c,d), which also ruled out canonical epithelial-to-mesenchymal transition (EMT). Further, these morphological changes correlated with increased cell motility and adhesion to substrate (Fig. 3c,d and Supplementary Fig. $6 \mathrm{~g}$ ). Although a small proportion of cells acquired increased size and an extended cytoplasm resembling the morphology of senescent cells, they were negative for Senescence-Associated $\beta$ galactosidase activity (Fig. 2a and Supplementary Fig. 6b,h). In contrast, such cell shape was accompanied by an actin organization typical of lamellipodia (Supplementary Fig. 6f), a cellular structure associated with high cell motility (Fig. 3c). 
We then assessed the metastatic potential of this phenotype induced by FOXO3a and $\beta$ catenin nuclear activity by injecting cells into the cecum wall of immunodeficient mice. Since DLD1F $\beta$ cells had limited capacity to initiate tumors in the cecum, we established a different HT29 colon cancer cell line with the same inducible systems to express exogenous FOXO3a and $\beta$-catenin $(\mathrm{HT} 29 \mathrm{~F} \beta)$. We used a pool of these cells, all of which expressed FOXO3a3A-ER and a constitutive Luciferase reporter, but only $41 \%$ of which contained the $\beta$-catenin ${ }^{\text {S33Y }}$-IRES-eGFP construct (Supplementary Fig. 7a,b). As in the case of DLD1F $\beta$ cells, DOX induced proliferation, protected from FOXO3a-induced apoptosis and over time enriched the $\beta$-catenin-expressing cell population (Supplementary Fig. 7c-e). Again, FOXO3a inhibition of proliferation was dominant (Supplementary Fig. 7d), and the activity of both transcriptional regulators induced cell scattering (Supplementary Fig. 7f). To examine their metastatic potential we injected these HT29F $\beta$ cells into the cecum wall of nude mice and induced nuclear accumulation of FOXO3a and/or $\beta$-catenin by treating the mice with $4 \mathrm{OHT}$, DOX or both. First, using bioluminescent live-imaging techniques, we observed an increase in tumor signal in DOX-treated animals, whereas the signal gradually decreased or even disappeared in a subset of mice treated with $4 \mathrm{OHT}$ (6 out of 11). Most of the mice treated with both drugs showed a weak tumor signal (Supplementary Fig. 8a,b).

As the luciferase signal from large primary tumors masked that from metastases in a subset of mice, we performed detailed necropsies and ex vivo analyses of internal organs by luminometry to improve metastases detection. Positive tissues were analyzed by histology to confirm metastases (Fig. $3 \mathrm{f}$ and Supplementary Fig. 8c). The combined nuclear accumulation of FOXO3a and $\beta$-catenin significantly increased the number of mice harboring metastases $(P=$ 0.022), the lungs being the most frequent dissemination site $(P=0.038)$. Peritoneal carcinomatosis $(P=0.07)$ and infiltrated lymph nodes $(P=0.157)$ also showed a tendency to harbour more metastases (Fig. 3e-g). A control experiment conducted with parental luciferaseexpressing HT29 cells failed to reveal such differences (Supplementary Fig. 8d). Immunohistological analysis confirmed nuclear FOXO3a accumulation in vivo following $4 \mathrm{OHT}$ treatment. This led to dramatic intra-tumoral cell death, which was rescued by $\beta$-catenin (Supplementary Fig. 9a,b). 
As observed in DLD1F $\beta$ cells, E-cadherin relocation, loss of epithelial organization and cell scattering again occurred only in the eGFP- $\beta$-catenin ${ }^{\mathrm{S} 33 \mathrm{Y}}$-positive cell population, in tumors growing in mice treated with both 4OHT and DOX (Supplementary Fig. 9c,d). Such cell scattering or tumor budding, which is a histopathological feature indicative of metastasis and poor prognosis $^{41,42}$, was significantly increased in primary tumors growing in the cecum wall of mice treated with $4 \mathrm{OHT}+\mathrm{DOX}$ (Fig. 3g,h). Nuclear FOXO3a and $\beta$-catenin colocalization was also found in scattered cells at the invasive front of human colon carcinomas (Supplementary Fig. 3i, j). By measuring FOXO3a and $\beta$-catenin colocalization signal in the tumor bulk, we observed its positive correlation with tumor budding at the invasive front. (Fig. 3i,j,k). For most of the primary human carcinomas analyzed, both factors presented similar nuclear levels in the tumor bulk and in the invasive front. Only a minor proportion showed increased accumulation of these factors at the invasive front as previously described for $\beta$-catenin (Supplementary Fig. 10b,d) ${ }^{43}$, although this difference was not statistically significant in our cohort of patients (Supplementary Fig. $10 a, c, d)$.

\section{FOXO3a and $\beta$-catenin regulate a set of target genes involved in metastasis.}

FOXO3a and $\beta$-catenin regulate the expression of target genes that commit cells to specific phenotypes. We therefore assumed that most of their combined activity inducing metastasis would be exerted through the regulation of a common set of target genes. Transcriptomic analyses in DLD1F $\beta-C 7$ cells were performed to define the gene expression profile attributable to either FOXO3a, $\beta$-catenin, or both in combination. Similar to a previous report ${ }^{44}$, FOXO3a alone completely transformed the gene expression pattern in DLD1F $\beta$ cells. In contrast, $\beta$-catenin alone produced only minor changes. However, $\beta$-catenin co-expression diverted FOXO3a-regulated genes to a different expression profile (Fig. 4a,b, Supplementary Table 1 and 2). In general, $\beta$ catenin enhanced the expression of known or novel FOXO3a target genes (Fig. 4c and Supplementary Fig. 11a,b and Supplementary Table 1 and 2). In contrast to these induced genes, others involved in cell differentiation such as MUC13, VIL1 or CDX2 were repressed by 
nuclear FOXO3a, and concomitant $\beta$-catenin further enhanced such inhibition (Supplementary Fig. 11b).

$\beta$-catenin enhances the expression of many FOXO3a target genes involved in cytoskeleton remodeling, cell shape and motility (Supplementary Table 3). The products of some of these genes form part of the same protein complexes that control the stability of cell-to-cell contacts. This is the case of the ARHGAP17-RICH1/MPP5-PALS/CD2AP complex, which controls tight junctions by modulating the activity of the small GTPase Cdc42 on actin cytoskeleton ${ }^{45}$. Some components of tight junctions like ZO1 or Claudins 1, 10 and 16 are also regulated (Supplementary Fig. 11c,d). Other factors, like IQGAP2, ANK3 or CAV1, which control the stability of adherens junctions and E-cadherin localization, are also simultaneously regulated by FOXO3a and $\beta$-catenin (Supplementary Fig. 11c,d).

We observed E-cadherin relocation from cell-to-cell contacts to cytoplasmic aggregates (Fig. $3 a, b$ and Supplementary Fig.6e,f and Supplementary Fig. 9d), a process that is regulated by IQGAP proteins that induce disassembly of adherens junctions and cell scattering ${ }^{46-48}$. Therefore, we selected this FOXO3a/ $\beta$-catenin target gene to evaluate its relevance as an effector of the observed changes in cell phenotype. We interfered with the expression of IQGAP2 protein, induced by $\mathrm{FOXO} 3 a$ and $\beta$-catenin in DLD1F $\beta$-C7 cells, using eight different specific lentiviral shRNAi constructs, separately or as a viral pool (Supplementary Fig. 12a,b and Supplementary Table 8b). IQGAP2 knock down partially preserved the amount of E-cadherin associated with the actin cortex at cell-to-cell contacts in DLD1F $\beta-C 7$ cells treated with 4OHT + DOX (Supplementary Fig. 12c,d). Besides, the induction of cell motility promoted by nuclear FOXO3a and $\beta$-catenin, was also significantly reduced when IQGAP2 was knocked down in DLD1F $\beta$-C7 cells (Supplementary Fig. 12e). Nevertheless, the reduction of IQGAP2 still allowed a significant increase in E-cadherin relocation and in cell motility of DLD1F $\beta-C 7$ cells upon $4 \mathrm{OHT}+\mathrm{DOX}$ treatment. Finally, we observed that IQGAP2 expression correlated with tumor budding in a set of 59 human colon carcinomas (Supplementary Fig. 12f).

IQGAP2 was observed in association with E-cadherin aggregates in the cytoplasm and alone in the nucleus of scattering DLD1F $\beta$ cells (Supplementary Fig. 13a,b). Human colon 
carcinomas also presented punctuate accumulation of E-cadherin and IQGAP2 protein complexes in the cytoplasm of cancer cells with disrupted epithelial organization (Supplementary Fig. 13c,d). Likewise, subcutaneous tumors from DLD1F $\beta$ cells presented increased expression of IQGAP2 in cells that accumulated FOXO3a and $\beta$-catenin upon simultaneous $4 \mathrm{OHT}$ and DOX treatment (Supplementary Fig. 13e).

FOXO3a and $\beta$-catenin regulated a defined set of metastasis-relevant genes - some synergistically and some additively (Fig. 4d,e, Supplementary Table 4). In addition to IQGAP2, we also studied CYR61 and CLDN1, which had been reported to be associated with cell-to-cell disassembly, cell scattering, motility and metastasis (Fig. 4f,g Supplementary Fig. 14) (7-50 $^{\text {. }}$ Furthermore, the levels of nuclear FOXO3a alone or FOXO3a and $\beta$-catenin colocalization signal correlated with the amount of each of these three target genes in a set of 59 primary human colon carcinomas (Fig. 4h and Supplementary Fig. 15a,c). $\beta$-catenin expression did not show any significant correlation (Supplementary Fig. 15b,d).

Gene set enrichment analysis of microarray data from DLD1F $\beta-C 7$ cells showed that FOXO3a regulated genes involved in apoptosis, including known targets like TNFSF10 (TRAIL), $B C L 2 L 11$ (BIM) or FASLG (FAS ligand), whereas its co-expression with nuclear $\beta$-catenin modulated additional gene sets controlling cell morphology, adhesion and motility (Supplementary Fig. 11a-d, Supplementary Fig. 16a-c and Supplementary Table 3). Consistently with the inhibition of FOXO3a-induced apoptosis (Fig. 2e,g), nuclear $\beta$-catenin attenuated the upregulation of the pro-apoptotic genes TNFSF10 and BCL2L11 while it synergized with FOXO3a to induce FASLG, which has pro- as well as anti-apoptotic functions, and the anti-apoptotic gene HIPK3 (Supplementary Fig. 11a and 16c). Moreover, $\beta$-catenin caused nuclear translocation of FAS-associated adaptor protein (FADD) and inhibited PARP1 cleavage induced by FOXO3a (Supplementary Fig. 16d,e). 
The AKT inhibitor API-2 promotes metastasis from colon-cancer cells with high nuclear $\beta$ catenin content.

We tested the hypothesis that the pharmacological inhibition of AKT and subsequent nuclear FOXO3a accumulation promotes metastasis cooperating with $\beta$-catenin. To this end, we induced FOXO3a accumulation by treating DLD1F $\beta$ cells with the AKT inhibitor API-2. In this context, we observed a cell scattering phenotype only when high nuclear $\beta$-catenin levels were induced by DOX treatment (Supplementary Fig. 17b). Some of the FOXO3a and $\beta$-catenin target genes defined in our metastasis signature (Fig. $4 \mathrm{~d}, \mathrm{e}$ ) were induced by API-2 and further enhanced by $\beta$ catenin in DLD1F $\beta-C 7$ colon cancer cells (Fig. 5a).

In tumors of HT29F $\beta$ cells growing in the cecum wall of nude mice, API-2 and DOX induced nuclear accumulation of FOXO3a and beta-catenin, respectively, as well as the loss of epithelial phenotype and the promotion of cell scattering (Fig. 5b and Supplementary Fig.17a). Such nuclear accumulation was heterogeneous across tumor regions, reflecting that $41 \%$ of injected cells were infected with $\beta$-catenin-expressing lentiviruses (Supplementary Fig. 7a).

Most importantly, although API-2 reduced primary tumor bioluminescence signal, it simultaneously promoted the development of metastasis when nuclear $\beta$-catenin was coexpressed (Fig. 5c,d). A significantly higher number of mice presented metastases $(P=0.015)$ when treated with API-2 + DOX (Fig. 5d). Mice affected in lungs $(P=0.082)$, lymph nodes $(P=$ $0.576)$ or presenting carcinomatosis $(P=0.15)$ were more frequent upon double treatment as compared with vehicle-treated mice, although the difference was not significant $(P<0.05)$ (Fig. 5d). Strikingly, API-2 treatment produced liver metastasis when $\beta$-catenin levels were high. This dissemination site had not been detected before in our HT29F $\beta$-cell model and recapitulated the main organ affected in human colon-cancer patients (Fig. $5 d-f)^{2,3}$. 


\section{$\beta$-catenin confers resistance to FOXO3a-induced apoptosis promoted by PI3K and AKT inhibitors in patient-derived colon-cancer initiating cells.}

$\mathrm{PI} 3 \mathrm{~K}$ and AKT inhibitors exert part of their anti-tumoral activity by inducing nuclear FOXO3a accumulation and apoptosis (Supplementary Fig. 17b-e) ${ }^{20}$. Based on our previous data, we tested whether $\beta$-catenin conferred resistance to PI3K inhibitors LY-249002 and NVP-BKM120 or to the AKT inhibitor API-2. We observed a dose-dependent resistance to API-2-induced apoptosis correlating with nuclear $\beta$-catenin content in DLD1F $\beta-C 7$ cells (Supplementary Fig. 17f-h). HCT116F cells with high endogenous amounts of mutant nuclear $\beta$-catenin or HT29F $\beta$ cells with medium levels were more resistant to NVP-BKM120 and API-2-induced apoptosis than DLD1F $\beta$ cells (Supplementary Fig. 18a,b and Supplementary Table 5). In L8 colon cancer cells that are heterogeneous respective to nuclear $\beta$-catenin levels and transcriptional activity, LY-249002 preferentially induced apoptosis in the low $\beta$-catenin expressing cell population (Supplementary Fig. 19a-c). Remarkably, the tankyrase inhibitor XAV-939, which reduces nuclear $\beta$-catenin levels and transcriptional activity (Supplementary Fig. 17d,e and Supplementary Fig. 19d-f) ${ }^{51}$, increased the sensitivity of HCT116F cells to NVP-BKM120- and API-2-induced apoptosis (Supplementary Fig. 18b).

Next, we applied our findings to sphere cultures of patient-derived colon cancer cells (Supplementary Fig. 18f). Our primary cultures regenerate carcinomas that are histologically indistinguishable from patients' primary tumors upon subcutaneous injection in NOD-SCID mice (Fig. 6a and Supplementary Fig. 18c). Since our sphere cultures demonstrated such self-renewal capacity and pluripotency, they are assumed to contain colon-cancer stem cells. They also recapitulated the original levels of nuclear $\beta$-catenin in xenograft tumors (Fig. $6 \mathrm{~b}$ and Supplementary Fig. 18d). Treatment of sphere cultures with LY-294002 or NVP-BKM120 and API-2 induced nuclear accumulation of FOXO3a and apoptosis in cells derived from patients T61, T68, T70 and T86, who originally presented low nuclear $\beta$-catenin levels in their primary carcinomas. In contrast, sphere cultures derived from patients T49 and T59 with high nuclear $\beta$ catenin were innately resistant to cell death mediated by LY-249002 and NVP-BKM120 or API-2, 
respectively. Importantly, reduction of $\beta$-catenin levels with XAV-939 reverted such resistance (Fig. 6b-d and Supplementary Fig. 18d,e,g). In contrast, sphere cultures were resistant to conventional chemotherapeutic agents like 5-FU or Oxaliplatin, and their combination with XAV939 did not sensitize them to apoptosis (Supplementary Fig. 18h).

We observed similar results in vivo. Thus, API-2 inhibited growth of subcutaneous tumors generated in NOD-SCID mice when injecting cells derived from patient T61 (low $\beta$-catenin), whereas those from patient T70 (intermediate $\beta$-catenin) presented partial response and those from patient T49 (high $\beta$-catenin) were resistant (Fig. 6d,e). Analysis of patient-derived xenograft tumor T49 revealed that API-2 treatment induced nuclear FOXO3a accumulation and increased cytoplasmatic IQGAP2 in tumor cell populations with disrupted epithelial organization (Fig. 6f,g). We also observed an enrichment of cells with high nuclear $\beta$-catenin levels in API-2-treated xenograft tumors from patients T49 compared to controls (vehicle; Fig. 6f,g). The reduction of S6 ribosomal protein phosphorylation confirmed the efficacy of API-2 treatment in inhibiting PI3K/AKT pathway signaling in vivo (Supplementary Fig. 20a,b). 


\section{DISCUSSION}

Metastases are responsible for over $90 \%$ of deaths in cancer patients. However, the molecular mechanisms that drive cancer cells towards metastasis are poorly understood. Our data reveal novel mechanisms by which crosstalk between $\mathrm{Wnt} / \beta$-catenin and $\mathrm{PI} / 3 \mathrm{~K} / \mathrm{AKT} / \mathrm{FOXO}$ oncogenic pathways promotes metastasis in colon cancer.

These two pathways interact at different levels. AKT phosphorylates GSK3 $\beta^{52}$ inhibiting its capacity to phosphorylate $\beta$-catenin and commit it to proteasomal degradation. Therefore, AKT activation leads to $\beta$-catenin stability and transcriptional activation in some cell contexts. Furthermore, SGK1 is a TCF/LEF- $\beta$-catenin target gene that encodes a kinase that phosphorylates FOXO3a and prevents its accumulation in the nucleus ${ }^{25}$. Wnt/ $\beta$-catenin pathway therefore inhibits FOXO3a transcriptional activity and induces apoptosis by increasing SGK1 activity in cancer cells. In addition, oxidative stress induces FOXO3a nuclear accumulation through its direct phosphorylation by activated $\mathrm{JNK}^{15,53}$. All these upstream signals may determine the nuclear amounts of $\mathrm{FOXO} 3 \mathrm{a}$ and $\beta$-catenin in human carcinomas. However, since in our experiments we used mutant forms of FOXO3a and $\beta$-catenin that cannot be phosphorylated by SGK1 or AKT and GSK3 $\beta$, respectively, we conclude that both transcription factors can induce the metastasis and drug-resistant phenotypes by themselves, independently of the main upstream signals that normally control their nuclear accumulation.

Although it has been demonstrated that abnormal activation of the Wnt/ $\beta$-catenin pathway is responsible for colon cancer initiation, less evidence supports its role in metastasis ${ }^{54}$. Wnt signal may participate by inducing TCF/LEF- $\beta$-catenin target genes involved in cancer cell migration and invasion like metalloproteases, urokinases or transcriptional repressors ${ }^{55-58}$.

The contribution of the PI3K/AKT/FOXO signaling to metastasis is controversial. On the one hand, some studies demonstrate that mutational activation of PI3K and induction of AKT activity mediate metastasis ${ }^{59}$, encouraging the use of therapeutic PI3K and AKT inhibitors. On the other hand, AKT can inhibit cell motility by blocking NFAT transcriptional activity ${ }^{60}$. Our results, which 
show that AKT inhibitors promote metastasis by nuclear FOXO3a accumulation and cooperation with $\beta$-catenin in colon cancer, support the second notion.

Few studies correlate FOXO3a function with metastasis or poor prognosis in cancer ${ }^{61,62}$. On the contrary, most studies define FOXO proteins as tumor suppressors, since they induce cellcycle arrest and apoptosis ${ }^{15,20-23}$. Indeed, the combined knock-down of FOXO1, 3, and 4 in mice is responsible for tumor initiation ${ }^{63}$. However, our results reveal a novel and unexpected role of FOXO3a as an inducer of metastasis when acting in concert with $\beta$-catenin. Importantly, we observed that their simultaneous nuclear accumulation in primary tumors correlated with Stages III and IV with local or distant metastases and significantly shorter overall survival of colon-cancer patients.

Loss of a differentiated epithelial phenotype and dissemination of cancer cells are early steps required for metastasis initiation in most solid tumors. We demonstrate that to acquire such metastatic capacity, $\mathrm{FOXO} 3 a$ and $\beta$-catenin act in concert, regulating functional sets of target genes involved in reorganizing the cytoskeleton, destabilizing cell-to-cell contacts, cell motility and migration, angiogenesis or evasion of the immune system (Supplementary Tables 1-4). These metastasis-related genes impose a cell-scattering phenotype that clearly differs from a canonical EMT, since levels of E-cadherin, Snail1, Snail2/Slug or Zeb1 are unchanged. Furthermore, we found that the expression of three of these target genes, IQGAP2, CLDN1 and CYR61, correlated positively with nuclear FOXO3a and $\beta$-catenin colocalization signal in primary carcinomas of colon-cancer patients. In particular, IQGAP2 colocalizes with E-cadherin in cytoplasmic aggregates in cancer cells that have lost their epithelial phenotype in vitro, in xenograft tumors and in human carcinomas. By knocking down its expression, we revealed IQGAP2 as a novel FOXO3a/ $\beta$-catenin target gene required for destabilizing E-cadherincontaining adherens junctions, for loss the epithelial phenotype and for enhanced cell motility. Furthermore, IQGAP2 expression correlated with cell scattering (tumor budding) in human colon carcinomas, indicating its role in invasion and metastasis. Since IQGAP2 knock-down partially altered the cell phenotype, we believe that what drives the final acquisition of cell motility and 
metastatic potential is the coordinated activity of several FOXO3a/ $\beta$-catenin target genes (Supplementary Fig. 11b-d).

Simultaneous accumulation of nuclear $\beta$-catenin and endogenous FOXO3a, upon AKT inhibition by API-2, promoted the synergistic induction of some of the aforementioned metastasisrelated target genes, suggesting their contribution to cancer-cell dissemination in nude mice. Indeed, API-2 accumulated nuclear FOXO3a and induced the expression of IQGAP2 in xenograft tumors from patient T49, which presented high endogenous levels of nuclear $\beta$-catenin. Such induction was accompanied by the loss of the epithelial phenotype similar to that observed in scattering HT29F $\beta$ cells that metastasized in nude mice treated with API-2 and DOX. In fact, tumor budding actually correlates with the level of FOXO3a and $\beta$-catenin colocalization, which supports the notion that the effect observed in our experimental cell systems takes place in human carcinomas.

Drug resistance is another crucial clinical feature that determines tumor relapse and patient survival. In particular, the mechanisms underlying resistance to novel PI3K or AKT inhibitors are largely unknown. One proposal is that activating mutations in RAS would trigger the down-stream RAF-MAPK pathway as an alternative way to survive treatment with pro-apoptotic PI3K or AKT inhibitors $^{27,64}$. In addition, some mutations in PIK3CA (p110alpha) have been implicated in conferring resistance to specific inhibitors in vitro ${ }^{65}$.

Part of the anti-tumoral action of PI3K and AKT inhibitors is based on nuclear FOXO accumulation and subsequent cell-cycle arrest and apoptosis ${ }^{20}$. Similarly, some anti-cancer drugs like 3-3'Diindolylmethane (B-DIM) ${ }^{66}$, or others widely used in the clinic such as doxorubicin or paclitaxel promote nuclear FOXO accumulation and apoptosis. In this scenario FOXO activation and cooperation with $\beta$-catenin may induce target genes that code for anti-oxidant scavenger enzymes such as SOD2 (MnSOD) to resist apoptosis ${ }^{20,53}$.

We show that nuclear $\beta$-catenin activity acts as a new mechanism of resistance to FOXO3ainduced apoptosis promoted by PI3K or AKT inhibitors. Thus, the induction of FOXO3a proapoptotic target genes such as TNFSF10 (TRAIL) or BCL2L11 (BIM) ${ }^{67}$ is reduced by nuclear $\beta$ - 
catenin, whereas FOXO3a and $\beta$-catenin cooperate synergistically to induce FASLG ${ }^{24}$. Such inhibitory effect of $\beta$-catenin could be a result of its binding to transcriptional co-repressors present at the promoters of these pro-apoptotic FOXO3a target genes ${ }^{12}$. We have identified the anti-apoptotic kinase HIPK3, which is responsible for FADD phosphorylation ${ }^{68}$ as a synergistically induced target gene of FOXO3a and $\beta$-catenin. This phosphorylation mediates FADD translocation to the nucleus, which confers resistance to death receptor-mediated apoptosis ${ }^{68-70}$. In this way, FOXO3a and $\beta$-catenin would block FASLG-induced apoptosis by inducing HIPK3 and thus diverting the down-stream FADD-mediated signal. Therefore, $\beta$-catenin would favor the FASLG anti-apoptotic function thus enhancing its role in cell motility, invasion and metastasis and explaining its poor prognostic value in colon cancer ${ }^{71-74}$. In summary, our data indicate that $\beta$ catenin activity modulates the dual role of FOXO3a as an inducer of cell death or cell survival.

We describe a new mechanism by which FOXO3a and $\beta$-catenin commit cancer cells to either apoptotic or metastatic phenotypes. Such a mechanism occurs in colon carcinomas, which are heterogeneous tissues containing cell populations with diverse biological properties ${ }^{75,76}$. A $\beta$ catenin paradox exists whereby individual cancer cells within genetically homogeneous populations (e.g. APC defective cells) accumulate different levels of nuclear $\beta$-catenin ${ }^{43,77}$. Numerous factors control the final level of nuclear $\beta$-catenin and, thus, the strength of the $\mathrm{Wnt} / \beta$ catenin signal. Classically, mutations in $A P C$, but also activating mutations in $K-R A S$ and different signals from tumor stroma like Hepatocyte Growth Factor or Lysophosphatidic Acid (LPA), entail nuclear $\beta$-catenin accumulation and cell diversity ${ }^{5,78-80}$. Our data demonstrate that PI3K or AKT inhibitors promote nuclear FOXO3a accumulation and induce apoptosis only in cells with low nuclear $\beta$-catenin levels, and yet they reduce proliferation and promote metastasis of high nuclear $\beta$-catenin cells (Supplementary Fig. 21).

We observed that only nuclear $\beta$-catenin-positive cells resisted FOXO3a-induced apoptosis while all the rest died either in vitro or in xenograft tumors. This selective apoptosis enriches resistant, high nuclear $\beta$-catenin cells upon long-term exposure to nuclear FOXO3a accumulation 
in vitro, and also in subcutaneous tumors from patient-derived cells. Such cell selection by apoptosis would explain why we did not detect cancer cells with high nuclear FOXO3a and low $\beta$ catenin levels in human colon carcinomas. Our data therefore do not support a switch of FOXO proteins from being inductors of apoptosis to being responsible for cell survival ${ }^{20}$, but rather a long-term selection of cancer cells with high nuclear $\beta$-catenin that are resistant to FOXO-induced apoptosis.

In colon carcinomas, cell populations with high nuclear $\beta$-catenin content present a gene expression pattern similar to progenitor cells ${ }^{81}$ and behave as cancer stem cells with enhanced self-renewal capacity and pluripotency ${ }^{79}$. Our data indicate that this population could be more resistant to FOXO-induced apoptosis and responsible for later relapse. FOXO3a arrests the cell cycle, thus imposing quiescence on cancer cells with high nuclear $\beta$-catenin levels, which would normally proliferate intensively. Interestingly, FOXO-induced quiescence is crucial for selfrenewal and drug-resistance in normal and cancer stem cells ${ }^{82-84}$. Excess levels of $\beta$-catenin above the amounts needed to drive TCF/LEF target genes in APC-deficient cells may therefore regulate novel sets of FOXO target genes responsible for conferring stem-cell properties to colon cancer cells ${ }^{85}$. We show that some of these target genes are related to metastasis, supporting the notion of metastatic cancer stem cells, which have indeed been reported at the tumor invasive front of colon carcinomas ${ }^{79,86}$.

Due to the limited availability of human colon cancer samples and the highly complex protocols needed to derive viable tumoral cells, few groups have yet explored the sensitivity of colon cancer patient-derived cells to anti-tumoral drugs in culture or, even less so, in vivo ${ }^{87,88}$. However, we applied our results to patient-derived colon-cancer initiating cells that complied with the fundamental properties of stem cells: self-renewal and pluripotency. These sphere cultures, which are enriched in cancer-initiating cells and which originated from tumors with high nuclear $\beta$ catenin content, were resistant to PI3K and AKT inhibitors in vitro and in subcutaneous xenograft tumors.

The information provided by these sphere cultures highlights the validity of studying targetdirected therapies in cells derived from colon tumors straight after surgical resection, since 
patients could therefore benefit from a personalized, experiment-based decision on the optimal treatment. In the particular case of PI3K or AKT inhibitors, undesirable induction of FOXO3a and $\beta$-catenin target genes and promotion of metastasis could be predicted and avoided.

We confirm that the tankyrase inhibitor XAV-939 reduces nuclear $\beta$-catenin levels ${ }^{51}$ and demonstrate that it sensitizes resistant cells specifically to FOXO3a-induced apoptosis promoted by $\mathrm{PI3K}$ or AKT inhibitors. In contrast, it does not present any benefit when combined with conventional chemotherapeutic agents like 5-Fluorouracil (5-FU) or Oxaliplatin in cultures of colon cancer-initiating cells. This points to a valid strategy to overcome drug resistance and metastasis by combining $\mathrm{PI} 3 \mathrm{~K}$ or $\mathrm{AKT}$ and $\mathrm{Wnt} / \beta$-catenin inhibitory drugs. Current Wnt signaling inhibitors have reduced activity in vivo, and a new generation of tankyrase inhibitors with satisfactory in vivo activity must be developed to translate our results to clinical practice.

The benefit of some PI3K and AKT inhibitors is currently being tested in clinical trials in colon cancer patients with advanced metastatic disease ${ }^{29}$ and they may be tested as part of adjuvant therapy in the future. Our findings call for the measurement of nuclear $\beta$-catenin as a biomarker of response to treatments provoking FOXO3a nuclear accumulation, in order to predict apoptosis versus metastasis. This should be advisable for PI3K and AKT inhibitors, and may be extended to other drugs such as Cetuximab or Receptor Tyrosine Kinase inhibitors that act upstream of a common oncogenic pathway ${ }^{89-91}$. 


\section{ACKNOWLEDGMENTS}

We acknowledge Dr. Wenlin Shao (Novartis Institutes for BioMedical Research, Inc) for providing the experimental drug XAV-939 and its inactive analogue LDW-643, and we thank Dr. K.F. Becker (Technische Universität München, Germany) for providing the anti-Snail1 antibody. We are also grateful to Dr. Paul J. Coffer (Utrecht, Netherlands) for kindly providing the pcDNA3FOXO3a(A3):ER ${ }^{\mathrm{TM}}$ expression plasmid as well as to Dr. Hans Clevers (Utrecht, Netherlands) for providing L8 colon cancer cells. Dr. Joan Seoane and Gerard Folch (VHIO, Barcelona, Spain) provided technical advice and reagents. We thank Dr. Raja Luthra (Molecular Diagnostics Laboratory, MD Anderson Cancer Center, Houston, TX, USA) for providing the CLIA panel of somatic mutations. We thank Dr. María Jesús Larriba for providing the reagents necessary for the analysis of Zeb1 and Slug expression and Dr. Maurizio Scaltriti for supplying the lentiviruses used to knock down IQGAP2 expression. We acknowledge Robin Rycroft and Amanda Wren for their valuable assistance in the preparation of the English manuscript. Experiments were supported by a VHIO Starting Grant and Grants from Fondo de Investigaciones SanitariasInstituto de Salud Carlos III (FIS-PI081356 and RD06/0020/0009) and Plan Nacional de Biomedicina, Ministerio de Ciencia e Innovación (SAF-18302). S.P.T. was supported by Fundació Olga Torres Fellowship, I.P. was funded by the Fundación Científica de la Asociación Española Contra el Cancer (AECC) and H.G.P. was supported by the Miguel Servet Program, Instituto de Salud Carlos III (ISCIII).

\section{AUTHOR CONTRIBUTIONS}

S.P.T., P.O-M. and I.P. contributed equally to the experiments, and S.P.T. also contributed writing the manuscript. I.C. also performed many experiments. O.A. helped to perform IQGAP2 knockdown experiments. S.L. Classified human tumors following histopathological criteria and built the tissue arrays. Y.F. Performed and analyzed live imaging assays $\left(\mathrm{IVIS}^{\circledR}\right)$ which were supervised by S.S.J.. J.R.H., S.R. and J.D.G. participated in live imaging experiments. L.M. and A.V. performed mutational analysis of human colon carcinomas. S.A. cloned and tested lentiviral constructs. S.R.C. provided human specimens. E.E. performed surgery on colon cancer patients. 
J.B. supervised the project. J.T. supervised the project and provided clinical follow up on all the patients included in the study. A.M. and H.G.P wrote the manuscript and supervised the project. H.G.P. was responsible for designing all the experiments and analyzing and interpreting all data.

\section{FIGURE LEGENDS}

Figure 1. High nuclear FOXO3a and $\beta$-catenin levels correlate with metastatic stages and shorter survival in colon cancer patients. (a-c) Representative immunostained sections (left panels; Scale bar, $100 \mu \mathrm{m}$ ) and respective magnifications (right panels; Scale bar, $20 \mu \mathrm{m}$ ) of tumors with (a) low $\beta$-catenin and low FOXO3a, (b) high $\beta$-catenin and low FOXO3a, and (c) high $\beta$-catenin and high FOXO3a expression. FOXO3a (green), $\beta$-catenin (red), Hoechst 33342 (blue). Spearman's coefficient of nuclear colocalization $(r)$ is indicated. Merged magnified images lack blue channel and yellow color indicates FOXO3a and $\beta$-catenin colocalization. (d) Plot depicting nuclear FOXO3a and $\beta$-catenin immunofluorescent signal intensity in human colon carcinomas. Correlation was evaluated by non-parametric Spearman test. Number of cases (n), coefficient of correlation (r), and $P$ values are indicated. Relative Units (r. u.) are calculated as explained in Methods section. (e) Column scatter plot showing the level of FOXO3a and $\beta$-catenin colocalization in tumors at different stages of colon cancer progression. Horizontal lines indicate

arithmetic mean values with error bars showing the $95 \%$ confidence interval $(\mathrm{Cl})$. Number of cases $(n)$ and $P$ value for non-parametric ANOVA analysis with Kruskal-Wallis test are indicated. Asterisk marks significant difference between groups quantified by Dunn's multiple comparison test. (f, h) Kaplan-Meier survival analysis of colon cancer patients separated into two groups by the median (f) or by the highest decile (h) for nuclear FOXO3a and $\beta$-catenin colocalization signal. Higher signal is in red $(n=58$ in $f, n=11$ in $h)$ and lower signal in black $(n=55$ in $f, n=$ 102 in h). $P$ values are calculated by Log-rank (Mantel-Cox) test. (g) Plot representing nuclear immunofluorescent signal for FOXO3a and $\beta$-catenin colocalization. Dots of the highest decile values are marked in red. 
Figure 2. FOXO3a and $\beta$-catenin control colon cancer cell proliferation and apoptosis. (a) Immunofluorescence analysis of FOXO3a (green) and $\beta$-catenin (red) expression in DLD1F $\beta$-C7 cells treated as indicated. Scale bar, $50 \mu \mathrm{m}$. Lower panels show magnifications. Scale bar, 20 $\mu \mathrm{m}$. Nuclei were stained with Hoechst 33342 (blue). Merged magnification pictures lack the blue channel and yellow color indicates FOXO3a and $\beta$-catenin colocalization. (b) Normalized relative CDKN1A and LEF1 RNA expression levels in DLD1F $\beta-C 7$ cells treated with DOX and/or 4OHT were measured by real-time RT-PCR. (c) Protein amounts of indicated proteins in DLD1F $\beta$-C7 cells assessed by western blot. Flag-tag antibody detects exogenous Flag- $\beta$-Catenin ${ }^{\mathrm{S} 33 Y}$. FOXO3a antibody recognizes endogenous protein (lower band) and FOXO3a3A-ER fusion protein (upper band). Tubulin served as loading control. (d) Graphic showing proliferation of DLD1F $\beta-C 7$ cells treated as indicated. (e) Chart depicting the percentage of apoptotic DLD1F $\beta$ C7 cells in response to the indicated treatments measured by flow cytometry. The $P$ value corresponds to an unpaired $t$ test. (b,d,e) Error bars show +/- standard deviation (s.d.) of triplicates from three independent experiments. (f) Tumor growth in nude mice $(n=8$, two tumors/animal) injected subcutaneously with DLD1F $\beta$ cells and treated as indicated. Error bars show means +/- s.d. of volume of 16 tumors per treatment. (g) Graphic representing the percentage of apoptotic eGFP- $\beta$-catenin ${ }^{\mathrm{S} 33 \mathrm{Y}}$-positive (green bars) or negative subpopulations (black bars) of DLD1F $\beta$ cells in tumors $(n=6)$ growing in nude mice treated as indicated. Bars show means and errors indicate $+/-$ s.d. of the volume of six tumors per treatment. $P$ values correspond to unpaired $t$ tests.

Figure 3. Nuclear FOXO3a and $\beta$-catenin drive cell scattering and metastasis. (a) Immunofluorescence analysis of DLD1F $\beta-C 7$ cells treated as indicated detecting E-cadherin (red) and phalloidin-FITC-stained actin filaments (green). Scale bar, $100 \mu \mathrm{m}$. (b) Immunofluorescence analysis of E-cadherin in DLD1F $\beta-C 7$ cells treated with 4OHT+DOX. Arrowheads indicate Ecadherin cytosolic aggregates. Scale bar, $10 \mu \mathrm{m}$. (a,b,j) Nuclei were stained with Hoechst 33342 (blue). (c) Scatter plot representing motility of DLD1F $\beta-C 7$ cells treated as indicated showing the 
distance covered by 50 individual cells in a time-lapse video recording one picture every 20 min during 120 h. Horizontal bars indicate means, errors show the 95\% Cl. (d) Graphic representing adhesion to the substrate of DLD1F $\beta-C 7$ cells treated as indicated at five minutes post-seeding. Bars show means $+/-$ s.d. of values of six replicates from two independent experiments. $(\mathbf{c}, \mathbf{d}, \mathbf{h}) P$ values for non-parametric ANOVA analyses with Kruskal-Wallis test are shown. Asterisks indicate significant differences between groups upon Dunn's multiple comparison tests. (e) Incidence of metastasis in mice injected in the cecum with HT29F $\beta$ cells and treated as indicated. L.N. = lymph node, Carc. $=$ carcinomatosis, including any tumor mass growing in the abdominal cavity eventually affecting adjacent organs. Ratios indicate the numbers of animals with affected tissue per total number in each group of treatment. $P$ values listed in brackets were calculated vs. vehicle by Fisher's exact test. Only metastases detected by luminometry and confirmed by histological exploration were taken into account. (f) Bioluminescence imaging (IVIS ${ }^{\circledR}$ ) of organs obtained upon necropsy of nude mice bearing orthotopic tumors from cecum-injected HT29F $\beta$ cells. Left: Images overlaid with gradual bioluminescent signal (blue < red) originated from luciferase-expressing metastatic cells. Right: Hematoxylin \& eosin staining of the corresponding histological sections. Carc. $=$ carcinomatosis; Ing. = inguinal. Scale bar, $100 \mu \mathrm{m} .(\mathbf{g})$ Hematoxylin \& eosin stained histological section of the invasive front of a primary tumor xenograft from HT29F $\beta$ cells growing in the cecum wall of nude mice treated with $4 \mathrm{OHT}+\mathrm{DOX}(\mathrm{e})$. (h) Column scatter plot presenting tumor budding in primary tumors described in (e). $n$ indicates the number of tumors analyzed. Horizontal bars show the mean and the $95 \% \mathrm{Cl}$. $P$ values for non-parametric ANOVA analyses with Kruskal-Wallis test are shown. Asterisks indicate significant differences between groups upon Dunn's multiple comparison tests. (i) Hematoxylin \& eosin stained histological section of the invasive front of a primary human colon carcinoma. Dashed square marks the area shown in panel $\mathbf{j} .(\mathbf{g}, \mathbf{i})$ Dashed line delineates tumor edge. $\mathrm{T}=$ tumor bulk; $\mathrm{M}=$ muscle. Black arrowheads indicate budding tumor cells. Scale bar, $100 \mu \mathrm{m} . \quad$ (j) Immunofluorescent staining of the invasive front of a human primary colon carcinoma for FOXO3a (green) and $\beta$-catenin (red). Nuclei were stained with Hoechst 33342 (blue). White arrowheads indicate budding tumor cells. Right panels show magnifications. The merged 
magnified image lacks the blue channel and yellow color indicates FOXO3a and $\beta$-catenin colocalization. Scale bar, $100 \mu \mathrm{m}$ and $20 \mu \mathrm{m}$ in magnification pictures. (j) Dot plot representing the correlation of nuclear FOXO3a and $\beta$-catenin immunofluorescence signal with the incidence of tumor budding in 65 human primary colon carcinomas. Correlation was evaluated by nonparametric Spearman test. Number of cases $(n)$, coefficient of correlation $(r)$, and $P$ values are indicated. Tumor budding and relative units (r. u.) of nuclear FOXO3a \& $\beta$-catenin content are calculated as explained in Methods section.

Figure 4. FOXO3a and $\beta$-catenin regulate a defined gene expression program. (a) Gene clustering diagram calculated on Robust Multi-Array (RMA)-normalized expression values upon genome wide microarray analysis. Cells were treated as labeled for 24 hours. Triplicates of each treatment are indicated as colored rectangles at the bottom. Significance level: two-tailed ANOVA $P$ value $\leq 0.05$. Scaling, low (green) to high (red). (b) Venn-Diagram representing the number of genes regulated by the indicated treatments $(24 \mathrm{~h})$ upon high-stringency analysis (cut-off Bonferroni: $P$ value $\leq 0.05)$ and a two-fold change versus control $(\geq 2)$ in at least one of the conditions (Supplementary Table 2). (c) Plot representing changes in the relative expression levels of regulated genes comparing $4 \mathrm{OHT}+\mathrm{DOX}$ and $4 \mathrm{OHT}$ treatments. Red, higher than twofold induction; green, lower than two-fold repression. (d) Metastasis signature. Heat map of RMAnormalized expression values for genes described to be involved in metastasis. Triplicates for each treatment are shown. Green tones, low expression; red tones, high expression. (e) Gene expression values of metastasis signature genes are shown as fold change for the indicated treatments. Official gene symbols and HGNC Gene Names are listed. n.s., not significant. (f) Mean relative mRNA expression levels of IQGAP2, CYR61 and CLDN1 transcripts measured by real-time RT-PCR in DLD1F $\beta$-C7 cells upon indicated treatments. Error bars, triplicate values +/s.d. obtained in three independent experiments. (g) Western blot analysis of the indicated proteins in DLD1F $\beta-C 7$ cells. Numbers below the blot represent relative amount of each protein versus vehicle-treated cells. All values are corrected by their respective Tubulin signal that served as loading control. (h) Dot plot representing immunofluorescent signal intensity for each indicated 
protein correlated to nuclear FOXO3a \& $\beta$-catenin colocalization signal intensity in 59 human colon carcinomas analyzed. Correlation was evaluated by non-parametric Spearman test. Number of patients $(n)$, coefficient of correlation $(r)$ and $P$ values are indicated. Relative units (r. u.) were calculated as explained in Methods section.

Figure 5. AKT inhibition by API-2 promotes metastasis of cells with high nuclear $\beta$-catenin. (a) Relative mRNA levels of the indicated genes measured by real-time RT-PCR in DLD1F $\beta-C 7$ cells treated with API-2 and/or DOX as shown. Error bars are +/- s.d. of triplicates from three independent experiments. (b) Immunofluorescence analysis of FOXO3a (red) and $\beta$-catenin (green) expression in primary tumors growing in the cecum of nude mice. Scale bar, $100 \mu \mathrm{m}$. Right panels: Magnification of cells within the primary tumors. Scale bar, $25 \mu \mathrm{m}$. Nuclei were stained with Hoechst 33342 (blue). (c) Kaplan-Meier analysis of bioluminiscence (BLI) representing the percentage of nude mice injected in the cecum with HT29F $\beta$ cells and treated as indicated that retain the signal along time. Number of animals used is indicated in panel d. (d) Incidence of metastasis in mice injected in the cecum with HT29F $\beta$ cells and treated as indicated. L.N. = lymph node, Carc. $=$ carcinomatosis, including any tumor mass growing in the abdominal cavity eventually affecting adjacent organs. Ratios indicate the numbers of animals with affected tissue per total number in each group of treatment. $P$ values listed in brackets were calculated vs. vehicle by Fisher's exact test. Only metastases detected by luminometry and confirmed by histological exploration were taken into account. (e) Ex vivo image of infiltrated liver overlaid with gradual false-colored bioluminescent signal (blue, low; red, high). (f) Hematoxylin \& eosin staining of liver metastasis from a cecum-injected mouse treated with API-2+DOX as described in (d). Scale bar, $200 \mu \mathrm{m}$. Insert shows a magnification with dashed line marking tumor-liver edge; $\mathrm{T}=$ tumor, $L=$ liver tissue. Scale bar, $100 \mu \mathrm{m}$.

Figure 6. High nuclear $\beta$-catenin level confers colon cancer patient-derived cells resistance to PI3K-AKT inhibitors. (a) Hematoxylin \& eosin staining of patients' primary carcinomas (left) and subcutaneous tumors (right, xenograft) generated in NOD-SCID mice from the corresponding 
patient-derived cells. Scale bar, $100 \mu \mathrm{m}$. (b) Immunofluorescent staining for $\beta$-catenin (red) in patients' primary carcinomas (left) and corresponding subcutaneous xenograft tumors in mice (right). Right inserts correspond to magnifications that show the amount of nuclear $\beta$-catenin. Nuclei were stained with Hoechst 33342 (blue). Scale bar, $100 \mu \mathrm{m}$ and right inserts $50 \mu \mathrm{m}$. (c) Percentages of apoptotic cells in patient-derived sphere cultures treated as indicated. Apoptosis was measured by flow cytometry. Bars represent the mean of three independent experiments. Error bars are +/- s.d. Cells were treated with the mentioned compounds as described in Methods section. (d) Graph representing the amount of nuclear $\beta$-catenin measured by immunofluorescence in the primary colon carcinomas of each indicated patient. Relative units ( $r$. u.) were calculated as explained in Methods section. (e) Cancer cells derived from the three indicated patients' tumors were injected subcutaneously in NOD-SCID mice and treated with API2 or vehicle ( $n=5$, two flanks/animal). Arrows mark the initiation of treatment. The represented fold change is calculated comparing tumor volume at each given time point versus the volume at first day of treatment. Relative units (r. u.) were calculated as explained in Methods section. Error bars are $+/-$ s.d. of ten tumors per treatment. $P$ values correspond to non-parametric MannWhitney test. Asterisks indicate significant differences between volumes of tumors growing in mice treated with vehicle versus API-2. (f) Upper panels: Immunofluorescent staining for FOXO3a (green) and $\beta$-catenin (red) in histological sections of subcutaneous xenografted tumors from patient T49 treated as indicated. Right panels correspond to magnifications that show amounts of nuclear FOXO3a and $\beta$-catenin. Scale bar, $100 \mu \mathrm{m}$ and right panel $50 \mu \mathrm{m}$. Lower panels show immunofluorescent staining for IQGAP2 (red) in the same xenograft tumors. Insert shows a magnification of cells with IQGAP2 accumulated in cytoplasmic aggregates. Scale bar, $100 \mu \mathrm{m}$ and insert $50 \mu \mathrm{m}$. Nuclei were stained with Hoechst 33342 (blue). (g) Column scatter plots representing the levels of expression for each indicated protein in xenografted tumors from patient T49 treated as labeled. Five pictures were quantified per each of the four tumors treated. $P$ values correspond to non-parametric Mann-Whitney test comparing the values of protein expression in each quantified picture. Relative units (r. u.) were calculated as explained in Methods section. 


\section{METHODS}

\section{Cell Culture}

Human colon-cancer cell lines were cultured in DMEM, 10\% FBS and penicillin/streptomycin (Invitrogen). DLD1 cells were transfected with pcDNA-FoxO3a(3A)ER ${ }^{\mathrm{TM}} 36$ and neomycinselected to obtain a pool of DLD1F cells. HT29 and HCT116 colon-cancer cell lines were transduced with pLHCX-HA-FoxO3a(3A):ER ${ }^{T M}$ retrovirus to generate HT29F and HCT116F. HT29F cells were additionally transfected with pGL4.51[luc2/CMV/Neo] (Promega). $\beta$-catenin ${ }^{\text {S33Y }}$ was introduced in DLD1F and HT29F by infection with pSIN-TRE-flag- $\beta$-Catenin ${ }^{\text {S33Y }}$-IRES-GFP inducible lentivirus to generate DLD1F $\beta$ and HT29F $\beta$ cell lines. Proliferation rates of cultured cells were assessed using the Cell Proliferation Kit II (XTT; Roche Molecular Biochemicals). Cell migration was quantified by filming cells for $120 \mathrm{~h}$ using a time-lapse microscope ( 3 frames/h, Olympus TiRF ${ }^{\mathrm{TM}}$ Microscope). The distance covered by 50 individual cells for each condition was measured using the cell-tracking plugin of the ImageJ software (Rasband, W.S., NIH, USA). Adhesion to substrate was quantified by using a spectrometer to measure quantity of crystal violet staining retained by cells attached to the plastic culture dish five minutes post-seeding. Senescence-associated (SA) $\beta$-galactosidase activity was determined using the Senescence Cells Histochemical Staining Kit (Sigma).

\section{Patient-derived cells}

Primary human colon-cancer cells were obtained from adenocarcinomas corresponding to six patients immediately after surgery. In all cases written informed consent was signed. The project including human samples was evaluated and accepted by the Research Ethics Committee from Vall d'Hebron University Hospital, Barcelona, Spain (Approval ID: PR(IR)79/2009). Staging and grade were assigned by histopathological evaluation at the Pathology Service of Vall d'Hebron Hospital. Cells were derived from patients' samples and sphere cultures in suspension were obtained as described previously ${ }^{87,92}$. 


\section{Animals, xenotransplantation and bioluminescence}

Animals were handled according to the European Union's animal care directive (86/609/EEC). Experiments were approved by the Ethical Committee of Animal Experimentation of Vall d'Hebron Institute of Research (ID: 40/08 CEEA and ID: 47/08/10 CEEA). NOD-SCID (NOD.CB17Prkdc $c^{\text {scid }} / \mathrm{NcrCrl}$ ) and Nude mice (Crl:NU-Foxn1nu) were purchased from Charles River Laboratories. Cells mixed with Matrigel (1:1 v/v-ratio; BD Biosciences) were injected subcutaneously into the flanks of NOD-SCID or Nude mice. For orthotopic transplantation, coloncancer cells were injected in the cecum wall of mice as previously described ${ }^{93}$. All mice injected were female littermates between 8 and 12 weeks of age. DOX ( $2 \mathrm{mg} / \mathrm{ml}$; Sigma-Aldrich) was administered ad libidum in drinking water containing $5 \%$ sucrose (Sigma-Aldrich). $4 \mathrm{OH}-$ Tamoxifen (100 $\mu \mathrm{g} / \mathrm{dose} ; 1 \mu \mathrm{g} / \mu \mathrm{l}$ in sesame oil; Sigma-Aldrich) and API2 (1 mg/kg in PBS-2\% DMSO; Tocris Bioscience) were injected intraperitoneally (i.p.) every second day. Tumor growth was calculated as fold increase of the average sphere volume $\left(V=4 / 3 \times \pi r^{3}\right.$, where $\left.r=(L+W) / 2\right)$ versus tumor volume at the beginning of treatment. Treatments were initiated once subcutaneous tumors reached $0.5 \mathrm{~cm}^{3}$. In vivo and ex vivo bioluminescence imaging was performed with the IVIS ${ }^{\circledR}$ Spectrum Imaging System and Living Image ${ }^{\circledR} 4.0$ software (Caliper Life Sciences). Animals were given $150 \mathrm{mg} / \mathrm{kg}$ i.p. of D-luciferin (Promega), and 9 minutes later either in vivo images were acquired under anaesthesia or animals were sacrificed and necropsy was performed for ex vivo imaging.

\section{Western blot, histology and immunofluorescence}

Western blot was carried out and quantified as described ${ }^{94}$. Nuclear/cytoplasmic fractionation was as described elsewhere ${ }^{95}$. Tumor budding was quantified as previously described ${ }^{41,42}$. Immunofluorescence was performed on fixed paraffin-embedded sections or on fixed cells cultured on glass coverslips as described ${ }^{94}$. Pictures were taken using an Olympus FluoViewFV1000 Confocal Microscope. All antibodies used are listed in Supplementary Table 7. Nuclear staining was done with Hoechst 33342 at $5 \mu \mathrm{g} / \mathrm{ml}$ (Sigma-Aldrich). 
To analyze FOXO3a, $\beta$-catenin, IQGAP2, CLDN1 and CYR61 expression in patients' colon tumors, serial histological sections of low-density tissue microarrays were immunostained with specific antibodies and counter-stained with Hoechst 33342. Signals were acquired using the HistoRX microscope and Automated Quantitative Analysis (AQUA ${ }^{\circledR}$ ) system. Fluorescence image data were analyzed with the MBF "ImageJ for Microscopy"-program collection of plugins (www.macbiophotonics.ca) using criteria described earlier ${ }^{94}$. Briefly, we defined Regions of Interest (ROI) in images of immunostained tissue arrays encompassing only tumoral tissue. First, using ImageJ software, we obtained the integrated density value and each channel-molecule (e.g. FOXO3a, green channel; $\beta$-catenin, red channel) and Hoechst 33342 (blue channel) for each ROI. Next, we measured the integrated density for Hoechst signal present in each ROI and normalized by a standard nucleus signal, defined as the average integrated density of ten nuclei taken at random. The resulting values correspond to the number of nuclei and, therefore, to the number of cells present in each ROI. Finally, we divided the values of the integrated density for each protein of interest (green or red channels) by the calculated number of cancer cells in the corresponding ROI. These values indicate the level of expression for each protein per cancer cell analyzed noted as relative units (r. u.) in the corresponding figures. To obtain FOXO3a and $\beta$ catenin colocalization signal we first calculated, using ImageJ software, the integrated density of the coincident signal between green (FOXO3a) and red ( $\beta$-catenin) channels in the corresponding ROI. Values were then normalized to the number of cancer cells, calculated as explained above (Hoechst, blue channel).

\section{Flow cytometry}

Analyses were done using FACScalibur and LSRII cytometers (BD Bioscience). Proportions of apoptotic cells were determined on trypsin-dissociated colon-cancer cell lines or minced tumor tissues using the following kits: Annexin V-eGFP (GenScript Corporation), Annexin V-PE (BD Pharmingen) or Annexin-V-APC (Bender MedSystems). Anti-human TRA-85-APC antibody (R\&D Systems) were used to discriminate human from mouse cells when samples were derived from xenograft tumors growing in mice. Dead cells were detected by using propidium iodide or DAPI 
staining. The cell-cycle profile was acquired with ethanol-fixed cells stained with propidium iodide. For data analysis we used FCS-express3 flow cytometer software (DeNovo Software).

\section{Quantitative RT-PCR and Transcriptomics}

RNA was isolated by the TRIZOL method (Invitrogen) and cDNA was synthesized using Superscript-III reverse transcriptase (Invitrogen). A 7900HT qPCR System was used with Power SYBR-green (Applied Biosystems) and specific pairs of primers (Supplementary Table 8). Relative gene expression was determined by the comparative $C_{T}$ method $^{96}$. We applied geNorm algorithms $^{97}$ to select succinate dehydrogenase flavoprotein subunit (SDHA) and peptidylprolyl isomerase $\mathrm{A}$ (cyclophilin $A, P P I A)$ as reference transcripts to use geometric means for normalization and to calculate normalized standard deviation from triplicates of three independent experiments.

The transcriptome of DLD1F $\beta-C 7$ cells was determined on a genome wide Human Gene 1.1 ST Array (Affimetrix). RNA of experimental triplicates treated with vehicle or with $4 \mathrm{OHT}(50 \mathrm{nM})$ and DOX $(2.5 \mu \mathrm{g} / \mathrm{ml} ; 12 \mathrm{~h}$ pretreatment) separately or in combination was analyzed at $12 \mathrm{~h}$ and $24 \mathrm{~h}$ after combined treatment. Microarray data was acquired using the Affimetrix GeneChip/GeneTitan platforms. We performed Gene Set Enrichment Analysis (GSEA, www.broadinstitute.org) comparing RMA-normalized probe sets to molecular signature gene sets (Gene Ontology Consortium). A subsequent cut-off at two-tailed ANOVA $P$ value $\leq 0.05$ yielded 8229 regulated probes at $12 \mathrm{~h}$ and 8479 probes at $24 \mathrm{~h}$, which were used for clustering. To obtain high-stringency gene lists encompassing fold-change values of 515 genes (12 h) and 874 genes (24 h) (Supplementary Table 1 and 2) data were collapsed-down to annotated genes (Unigene; $\mathrm{NCBI})$ and further cut off at a significance level of Bonferroni adjusted $P$ value $\leq 0.05(\approx$ FDR $P$ value $\leq 0.00005)$ and minimum two-fold change vs. control (vehicle) in at least one condition. Raw and normalized MIAME-compliant microarray data were deposited in ARRAYEXPRESS (www.ebi.ac.uk/arrayexpress/) under Accession Number E-MEXP-3262. 


\section{Mutational status of patient-derived cells and cancer cell lines}

Samples were genotyped for 740 mutations associated with tumors, which affected 57 genes. OncoCarta (Sequenom), CLIA (MD Anderson Cancer Center, Houston, TX) and VHIO-Card panels of somatic mutations (Supplementary Table 6) were analyzed with a MassARRAY spectrometer (Sequenom) as published ${ }^{98}$. Mutation data were obtained from the Sanger Institute's COSMIC database (www.sanger.ac.uk/cosmic). Microsatellite instability was analyzed using the MSI-Analysis System (Promega). Loss of nuclear expression of mismatch-repair proteins (MLH1, MSH2, MSH6, PMS2) was assessed by immunohistochemistry.

\section{Plasmids}

The Tet-inducible lentiviral plasmid pSIN-TRE-flag- $\beta-C a t e n i n^{\mathrm{S} 33 Y}$-IRES-GFP was constructed using an IRES-GFP cassette-containing derivate ${ }^{99}$ of pRRL-cPPT-hPGK-TMPrtTA-WPRE plasmid $^{100}$ introducing the human flag- $\beta-$ Catenin ${ }^{533 Y}$ cds (Mlul). Retroviral plasmid pLHCX-HAFoxO3a(A3):ER ${ }^{\text {TM }}$ was cloned inserting FOXO3a(A3):ER ${ }^{\text {TM }}$ construct $^{36}$ Hindlll/Clal in pLHCX (Clontech). The lentiviral reporter 7TGP was previously described ${ }^{101}$. Lentiviral shRNAmirconstructs in the pGIPZ vector to knock-down IQGAP2 expression were purchased from Open Biosystems (Supplementary table 8b). ZEB1 and SLUG expression vectors were a kind gift from A. Muñoz laboratory (Madrid, Spain).

\section{Reagents and treatments}

Unless specified otherwise, cells were treated under the following conditions: DOX, $2.5 \mu \mathrm{g} / \mathrm{ml}$ for $36 \mathrm{~h}$ (DOX, Sigma-Aldrich), $12 \mathrm{~h}$ previous to 4-Hydroxy-Tamoxifen, $50 \mathrm{nM}$ for $24 \mathrm{~h}$ (4OHT, Sigma-Aldrich). XAV-939, 3.3 $\mu \mathrm{M}$ or LDW-643 (Novartis) for $120 \mathrm{~h}, 48 \mathrm{~h}$ previous to LY-294002, $20 \mu \mathrm{M}$ (Merck), API-2, $20 \mu \mathrm{M}$ (Tocris Bioscience), NVP-BKM120, $0.8 \mu \mathrm{M}$ (Selleck Chemicals), 5Fluorouracil, $50 \mu \mathrm{g} / \mathrm{ml}$ (5-FU; Sigma-Aldrich) or Oxaliplatin, $100 \mu \mathrm{M}$ (Sigma-Aldrich) for $72 \mathrm{~h}$. LDW-643 is an analogue of XAV-939 with no biological activity that was used to treat control cells in all experiments in which XAV-939 was tested. Mitomycin $\mathrm{C}(10 \mu \mathrm{g} / \mathrm{ml}$ for $3 \mathrm{~h})$ was used $24 \mathrm{~h}$ 
prior to additional treatments. Human primary fibroblasts were treated with Doxorubicin at $0.1 \mu \mathrm{M}$ for $24 \mathrm{~h}$ to induce senescent phenotype within the ten following days.

\section{Viral infection}

Lentiviral particles were produced by transfecting 293T cells with lentiviral constructs and packaging vectors (psPAX2 and pMD2.G, Addgene). Analogously, we produced retrovirus using retroviral plasmids and pCL-Ampho packaging construct (Imgenex Corp.).

\section{Statistics}

To calculate the correlation coefficient $(r)$ between fluorescent signal values of different proteins or with tumor budding in tissue sections of human carcinomas (Fig. 1h, Fig. 3k, Fig. 4h and Supplementary Fig. 1a,b, 12f, 15a,b), we used a two-tailed non-parametric Spearman test which makes no assumption about the distribution of the values. Using MBF "ImageJ for Microscopy"program we also obtained Spearman's correlation coefficient (r) corresponding to colocalization between nuclear FOXO3a and $\beta$-catenin (Fig.1a), E-cadherin and actin (Supplementary Fig. 6f, 12c,d), E-cadherin and IQGAP2 (Supplementary Fig. 13b,d) or IQGAP2 and Hoechst 33342 (Supplementary Fig. 13b,d). We used a non-parametric Kruskal-Wallis test to compare the values obtained for nuclear $\beta$-catenin, FOXO3a or their colocalization in human carcinomas at different tumor stages (Fig. 1e and Supplementary Figure 1c,d), to compare different treatments in cell motility and adhesion assays (Fig. 3c,d), to compare tumor budding in primary tumors growing in the cecum wall of nude mice (Fig. 3h), or nuclear $\beta$-catenin content in different cell lines (Supplementary Fig. 18a). We used this test because it allowed us to compare three or more groups of values which were unpaired and did not follow any particular distribution. We also used a Dunn's multiple comparison post-test to identify differences in the sum of ranks between each pair of group of values. To analyze survival of colon cancer patients (Fig. 1f,h and Supplementary Fig. 1e,f) we used the Kaplan-Meier method and compared the curves using a Log-rank (MantelCox) test. This is the best test assuming that the hazard function (deaths per time) is the same at all times. We used the non-parametric Mann Whitney test to compare the unmatched groups of 
values corresponding to xenograft tumour volumes or luminescence signal (Fig. 6e and Supplementary Fig. 8b), tissue protein expression (Fig. 6g, Supplementary Fig. 2a, 5e, 10d, 17a,c,e, 20b) and cell motility of IQGAP2 knock down cells (Supplementary Fig. 12e). To evaluate the effect of treatments on the proportion of apoptotic cells (Fig. 2e,g), we used an unpaired $t$ test to compare the means of the two groups of values. We used a Fisher's exact test to analyze the differences in metastasis frequency between groups of treated mice (Fig. 3e, Fig. $5 d$ and Supplementary Fig. $8 d$ ). All groups of mice were compared with vehicle-treated animals.

\section{REFERENCES}

1. Jemal, A., et al. Global cancer statistics. CA: a cancer journal for clinicians $\mathbf{6 1}$, 69-90 (2011).

2. Janne, P.A. \& Mayer, R.J. Chemoprevention of colorectal cancer. The New England journal of medicine 342, 1960-1968 (2000).

3. Levine, J.S. \& Ahnen, D.J. Clinical practice. Adenomatous polyps of the colon. The New England journal of medicine 355, 2551-2557 (2006).

4. Radtke, F. \& Clevers, H. Self-renewal and cancer of the gut: two sides of a coin. Science 307, 1904-1909 (2005).

5. Clevers, H. Wnt/beta-catenin signaling in development and disease. Cell 127, 469-480 (2006).

6. MacDonald, B.T., Tamai, K. \& He, X. Wnt/beta-catenin signaling: components, mechanisms, and diseases. Dev Cell 17, 9-26 (2009).

7. $\quad$ Reya, T. \& Clevers, H. Wnt signalling in stem cells and cancer. Nature 434, 843850 (2005).

8. Gregorieff, A. \& Clevers, H. Wnt signaling in the intestinal epithelium: from endoderm to cancer. Genes Dev 19, 877-890 (2005).

9. Palmer, H.G. Vitamin D3 promotes the differentiation of colon carcinoma cells by the induction of E-cadherin and the inhibition of beta-catenin signaling. The Journal of Cell Biology 154, 369-388 (2001).

10. Palmer, H.G., Anjos-Afonso, F., Carmeliet, G., Takeda, H. \& Watt, F.M. The vitamin $\mathrm{D}$ receptor is a Wnt effector that controls hair follicle differentiation and specifies tumor type in adult epidermis. PLoS One 3, e1483 (2008).

11. Jones, P.H., Simons, B.D. \& Watt, F.M. Sic transit gloria: farewell to the epidermal transit amplifying cell? Cell stem cell 1, 371-381 (2007).

12. Olson, L.E., et al. Homeodomain-mediated beta-catenin-dependent switching events dictate cell-lineage determination. Cell 125, 593-605 (2006).

13. Mulholland, D.J., Dedhar, S., Coetzee, G.A. \& Nelson, C.C. Interaction of nuclear receptors with the $\mathrm{Wnt} /$ beta-catenin/Tcf signaling axis: Wnt you like to know? Endocr Rev 26, 898-915 (2005).

14. Essers, M.A., et al. Functional interaction between beta-catenin and FOXO in oxidative stress signaling. Science 308, 1181-1184 (2005). 
15. Calnan, D.R. \& Brunet, A. The FoxO code. Oncogene 27, 2276-2288 (2008).

16. Burgering, B.M. A brief introduction to FOXOlogy. Oncogene 27, 2258-2262 (2008).

17. van der Horst, A. \& Burgering, B.M. Stressing the role of FoxO proteins in lifespan and disease. Nat Rev Mol Cell Biol 8, 440-450 (2007).

18. Huang, H. \& Tindall, D.J. Dynamic FoxO transcription factors. Journal of cell science 120, 2479-2487 (2007).

19. van der Vos, K.E. \& Coffer, P.J. The extending network of FOXO transcriptional target genes. Antioxidants \& redox signaling 14, 579-592 (2011).

20. Gomes, A.R., Brosens, J.J. \& Lam, E.W. Resist or die: FOXO transcription factors determine the cellular response to chemotherapy. Cell cycle (Georgetown, Tex 7, 3133-3136 (2008).

21. Myatt, S.S., Brosens, J.J. \& Lam, E.W. Sense and sensitivity: FOXO and ROS in cancer development and treatment. Antioxidants \& redox signaling 14, 675-687 (2011).

22. Myatt, S.S. \& Lam, E.W. The emerging roles of forkhead box (Fox) proteins in cancer. Nat Rev Cancer 7, 847-859 (2007).

23. Greer, E.L. \& Brunet, A. FOXO transcription factors at the interface between longevity and tumor suppression. Oncogene 24, 7410-7425 (2005).

24. Brunet, A., et al. Akt promotes cell survival by phosphorylating and inhibiting a Forkhead transcription factor. Cell 96, 857-868 (1999).

25. Dehner, M., Hadjihannas, M., Weiske, J., Huber, O. \& Behrens, J. Wnt signaling inhibits Forkhead box O3a-induced transcription and apoptosis through upregulation of serum- and glucocorticoid-inducible kinase 1. J Biol Chem 283, 19201-19210 (2008).

26. Walther, A., et al. Genetic prognostic and predictive markers in colorectal cancer. Nat Rev Cancer 9, 489-499 (2009).

27. Liu, P., Cheng, H., Roberts, T.M. \& Zhao, J.J. Targeting the phosphoinositide 3kinase pathway in cancer. Nat Rev Drug Discov 8, 627-644 (2009).

28. Ihle, N.T. \& Powis, G. Take your PIK: phosphatidylinositol 3-kinase inhibitors race through the clinic and toward cancer therapy. Molecular cancer therapeutics 8, 1-9 (2009).

29. Dienstmann, R., Rodon, J., Markman, B. \& Tabernero, J. Recent developments in anti-cancer agents targeting PI3K, Akt and mTORC1/2. Recent Pat Anticancer Drug Discov 6, 210-236 (2011).

30. Markman, B., Atzori, F., Perez-Garcia, J., Tabernero, J. \& Baselga, J. Status of PI3K inhibition and biomarker development in cancer therapeutics. Ann Oncol 21, 683-691 (2010).

31. Morris, R.J., et al. Capturing and profiling adult hair follicle stem cells. Nat Biotechnol 22, 411-417 (2004).

32. Zheng, Y., et al. Novel phosphatidylinositol 3-kinase inhibitor NVP-BKM120 induces apoptosis in myeloma cells and shows synergistic anti-myeloma activity with dexamethasone. J Mol Med (Berl) (2011).

33. Garrett, C.R., et al. Phase I pharmacokinetic and pharmacodynamic study of triciribine phosphate monohydrate, a small-molecule inhibitor of AKT 
phosphorylation, in adult subjects with solid tumors containing activated AKT. Invest New Drugs (2010).

34. Hoffman, K., et al. Phase I-II study: triciribine (tricyclic nucleoside phosphate) for metastatic breast cancer. Cancer Chemother Pharmacol 37, 254-258 (1996).

35. Bendell, J.C., et al. Phase I, Dose-Escalation Study of BKM120, an Oral PanClass I PI3K Inhibitor, in Patients With Advanced Solid Tumors. J Clin Oncol 30, 282-290 (2012).

36. Dijkers, P.F., Medema, R.H., Lammers, J.W., Koenderman, L. \& Coffer, P.J. Expression of the pro-apoptotic Bcl-2 family member Bim is regulated by the forkhead transcription factor FKHR-L1. Curr Biol 10, 1201-1204 (2000).

37. Seoane, J., Le, H.V., Shen, L., Anderson, S.A. \& Massague, J. Integration of Smad and forkhead pathways in the control of neuroepithelial and glioblastoma cell proliferation. Cell 117, 211-223 (2004).

38. Hoogeboom, D., et al. Interaction of FOXO with beta-catenin inhibits betacatenin/T cell factor activity. J Biol Chem 283, 9224-9230 (2008).

39. Kops, G.J., et al. Control of cell cycle exit and entry by protein kinase Bregulated forkhead transcription factors. Mol Cell Biol 22, 2025-2036 (2002).

40. Nobes, C.D. \& Hall, A. Rho, rac, and cdc42 GTPases regulate the assembly of multimolecular focal complexes associated with actin stress fibers, lamellipodia, and filopodia. Cell 81, 53-62 (1995).

41. Ueno, H., Murphy, J., Jass, J.R., Mochizuki, H. \& Talbot, I.C. Tumour 'budding' as an index to estimate the potential of aggressiveness in rectal cancer. Histopathology 40, 127-132 (2002).

42. Prall, F., Nizze, H. \& Barten, M. Tumour budding as prognostic factor in stage I/II colorectal carcinoma. Histopathology 47, 17-24 (2005).

43. Brabletz, T., et al. Variable beta-catenin expression in colorectal cancers indicates tumor progression driven by the tumor environment. Proc Natl Acad Sci USA 98, 10356-10361 (2001).

44. Delpuech, O., et al. Induction of Mxi1-SR alpha by FOXO3a contributes to repression of Myc-dependent gene expression. Molecular and cellular biology 27, 4917-4930 (2007).

45. Wells, C.D., et al. A Rich1/Amot complex regulates the Cdc42 GTPase and apical-polarity proteins in epithelial cells. Cell 125, 535-548 (2006).

46. Kaibuchi, K., Kuroda, S., Fukata, M. \& Nakagawa, M. Regulation of cadherinmediated cell-cell adhesion by the Rho family GTPases. Curr Opin Cell Biol 11, 591-596 (1999).

47. Yamashiro, S., Abe, H. \& Mabuchi, I. IQGAP2 is required for the cadherinmediated cell-to-cell adhesion in Xenopus laevis embryos. Dev Biol 308, 485-493 (2007).

48. Natale, D.R. \& Watson, A.J. Rac-1 and IQGAP are potential regulators of Ecadherin-catenin interactions during murine preimplantation development. Gene Expr Patterns 2, 17-22 (2002).

49. Tsai, M.S., Hornby, A.E., Lakins, J. \& Lupu, R. Expression and function of CYR61, an angiogenic factor, in breast cancer cell lines and tumor biopsies. Cancer Res 60, 5603-5607 (2000). 
50. Dhawan, P., et al. Claudin-1 regulates cellular transformation and metastatic behavior in colon cancer. J Clin Invest 115, 1765-1776 (2005).

51. Huang, S.M., et al. Tankyrase inhibition stabilizes axin and antagonizes Wnt signalling. Nature 461, 614-620 (2009).

52. Cross, D.A., Alessi, D.R., Cohen, P., Andjelkovich, M. \& Hemmings, B.A. Inhibition of glycogen synthase kinase- 3 by insulin mediated by protein kinase B. Nature 378, 785-789 (1995).

53. Kops, G.J., et al. Forkhead transcription factor FOXO3a protects quiescent cells from oxidative stress. Nature 419, 316-321 (2002).

54. Chu, P., et al. Characterization of a subpopulation of colon cancer cells with stem cell-like properties. Int J Cancer 124, 1312-1321 (2009).

55. Wu, B., Crampton, S.P. \& Hughes, C.C. Wnt signaling induces matrix metalloproteinase expression and regulates T cell transmigration. Immunity 26, 227-239 (2007).

56. Brabletz, T., Jung, A., Dag, S., Hlubek, F. \& Kirchner, T. beta-catenin regulates the expression of the matrix metalloproteinase-7 in human colorectal cancer. Am J Pathol 155, 1033-1038 (1999).

57. Mann, B., et al. Target genes of beta-catenin-T cell-factor/lymphoid-enhancerfactor signaling in human colorectal carcinomas. Proc Natl Acad Sci US A 96, 1603-1608 (1999).

58. Howe, L.R., Watanabe, O., Leonard, J. \& Brown, A.M. Twist is up-regulated in response to Wnt1 and inhibits mouse mammary cell differentiation. Cancer research 63, 1906-1913 (2003).

59. Samuels, Y., et al. Mutant PIK3CA promotes cell growth and invasion of human cancer cells. Cancer cell 7, 561-573 (2005).

60. Yoeli-Lerner, M., et al. Akt blocks breast cancer cell motility and invasion through the transcription factor NFAT. Mol Cell 20, 539-550 (2005).

61. Chen, J., et al. Constitutively nuclear FOXO3a localization predicts poor survival and promotes Akt phosphorylation in breast cancer. PloS one 5, e12293 (2010).

62. Storz, P., Doppler, H., Copland, J.A., Simpson, K.J. \& Toker, A. FOXO3a promotes tumor cell invasion through the induction of matrix metalloproteinases. Molecular and cellular biology 29, $4906-4917$ (2009).

63. Paik, J.H., et al. FoxOs are lineage-restricted redundant tumor suppressors and regulate endothelial cell homeostasis. Cell 128, 309-323 (2007).

64. Jun, T., Gjoerup, O. \& Roberts, T.M. Tangled webs: evidence of cross-talk between c-Raf-1 and Akt. Sci STKE 1999, PE1 (1999).

65. Zunder, E.R., Knight, Z.A., Houseman, B.T., Apsel, B. \& Shokat, K.M. Discovery of drug-resistant and drug-sensitizing mutations in the oncogenic PI3K isoform p110 alpha. Cancer cell 14, 180-192 (2008).

66. Li, Y., et al. Regulation of FOXO3a/beta-catenin/GSK-3beta signaling by 3,3'diindolylmethane contributes to inhibition of cell proliferation and induction of apoptosis in prostate cancer cells. J Biol Chem 282, 21542-21550 (2007).

67. Obexer, P., Geiger, K., Ambros, P.F., Meister, B. \& Ausserlechner, M.J. FKHRL1-mediated expression of Noxa and Bim induces apoptosis via the mitochondria in neuroblastoma cells. Cell death and differentiation 14, 534-547 (2007). 
68. Rochat-Steiner, V., et al. FIST/HIPK3: a Fas/FADD-interacting serine/threonine kinase that induces FADD phosphorylation and inhibits fas-mediated Jun NH(2)terminal kinase activation. $J$ Exp Med 192, 1165-1174 (2000).

69. Curtin, J.F. \& Cotter, T.G. JNK regulates HIPK3 expression and promotes resistance to Fas-mediated apoptosis in DU 145 prostate carcinoma cells. $J$ Biol Chem 279, 17090-17100 (2004).

70. Tourneur, L. \& Chiocchia, G. FADD: a regulator of life and death. Trends in immunology 31, 260-269 (2010).

71. Peter, M.E., et al. The CD95 receptor: apoptosis revisited. Cell 129, 447-450 (2007).

72. Barnhart, B.C., et al. CD95 ligand induces motility and invasiveness of apoptosisresistant tumor cells. Embo $J$ 23, 3175-3185 (2004).

73. Liu, K., McDuffie, E. \& Abrams, S.I. Exposure of human primary colon carcinoma cells to anti-Fas interactions influences the emergence of pre-existing Fas-resistant metastatic subpopulations. Journal of immunology 171, 4164-4174 (2003).

74. Yokomizo, H., et al. Fas ligand expression is a risk factor for liver metastasis in colorectal cancer with venous invasion. Anticancer research 23, 5221-5224 (2003).

75. Clevers, H. The cancer stem cell: premises, promises and challenges. Nat Med 17, 313-319 (2011).

76. Shackleton, M., Quintana, E., Fearon, E.R. \& Morrison, S.J. Heterogeneity in cancer: cancer stem cells versus clonal evolution. Cell 138, 822-829 (2009).

77. Fodde, R. \& Brabletz, T. Wnt/beta-catenin signaling in cancer stemness and malignant behavior. Curr Opin Cell Biol 19, 150-158 (2007).

78. Phelps, R.A., et al. A two-step model for colon adenoma initiation and progression caused by APC loss. Cell 137, 623-634 (2009).

79. Vermeulen, L., et al. Wnt activity defines colon cancer stem cells and is regulated by the microenvironment. Nat Cell Biol 12, 468-476 (2010).

80. Malbon, C.C. Beta-catenin, cancer, and G proteins: not just for frizzleds anymore. Sci STKE 2005, pe35 (2005).

81. Kaiser, S., et al. Transcriptional recapitulation and subversion of embryonic colon development by mouse colon tumor models and human colon cancer. Genome biology 8, R131 (2007).

82. Tothova, Z. \& Gilliland, D.G. FoxO transcription factors and stem cell homeostasis: insights from the hematopoietic system. Cell stem cell 1, 140-152 (2007).

83. Pellicano, F., et al. FOXO transcription factor activity is partially retained in quiescent CML stem cells and induced by tyrosine kinase inhibitors in CML progenitor cells. Blood (2009).

84. Naka, K., et al. TGF-beta-FOXO signalling maintains leukaemia-initiating cells in chronic myeloid leukaemia. Nature 463, 676-680 (2010).

85. Van der Flier, L.G., et al. The Intestinal Wnt/TCF Signature. Gastroenterology 132, 628-632 (2007). 
86. Brabletz, T., Jung, A., Spaderna, S., Hlubek, F. \& Kirchner, T. Opinion: migrating cancer stem cells - an integrated concept of malignant tumour progression. Nat Rev Cancer 5, 744-749 (2005).

87. Todaro, M., et al. Colon cancer stem cells dictate tumor growth and resist cell death by production of interleukin-4. Cell stem cell 1, 389-402 (2007).

88. Varnat, F., et al. Human colon cancer epithelial cells harbour active HEDGEHOG-GLI signalling that is essential for tumour growth, recurrence, metastasis and stem cell survival and expansion. EMBO Mol Med 1, 338-351 (2009).

89. Jhawer, M., et al. PIK3CA mutation/PTEN expression status predicts response of colon cancer cells to the epidermal growth factor receptor inhibitor cetuximab. Cancer research 68, 1953-1961 (2008).

90. Krol, J., et al. The transcription factor FOXO3a is a crucial cellular target of gefitinib (Iressa) in breast cancer cells. Molecular cancer therapeutics 6, 31693179 (2007).

91. Essafi, A., et al. Direct transcriptional regulation of Bim by FoxO3a mediates STI571-induced apoptosis in Bcr-Abl-expressing cells. Oncogene 24, 2317-2329 (2005).

92. Kreso, A. \& O'Brien, C.A. Colon cancer stem cells. Curr Protoc Stem Cell Biol Chapter 3, Unit 31 (2008).

93. Cespedes, M.V., et al. Orthotopic microinjection of human colon cancer cells in nude mice induces tumor foci in all clinically relevant metastatic sites. $\mathrm{Am} \mathrm{J}$ Pathol 170, 1077-1085 (2007).

94. Barbachano, A., et al. SPROUTY-2 and E-cadherin regulate reciprocally and dictate colon cancer cell tumourigenicity. Oncogene 29, 4800-4813 (2010).

95. Dignam, J.D., Lebovitz, R.M. \& Roeder, R.G. Accurate transcription initiation by RNA polymerase II in a soluble extract from isolated mammalian nuclei. Nucleic acids research 11, 1475-1489 (1983).

96. Schmittgen, T.D. \& Livak, K.J. Analyzing real-time PCR data by the comparative C(T) method. Nat Protoc 3, 1101-1108 (2008).

97. Vandesompele, J., et al. Accurate normalization of real-time quantitative RT-PCR data by geometric averaging of multiple internal control genes. Genome Biol 3, RESEARCH0034 (2002).

98. Devitt, G., Thomas, M., Klibanov, A.M., Pfeiffer, T. \& Bosch, V. Optimized protocol for the large scale production of HIV pseudovirions by transient transfection of HEK293T cells with linear fully deacylated polyethylenimine. $J$ Virol Methods 146, 298-304 (2007).

99. Aguilar, S., et al. Bone marrow stem cells expressing keratinocyte growth factor via an inducible lentivirus protects against bleomycin-induced pulmonary fibrosis. PLoS One 4, e8013 (2009).

100. Barde, I., et al. Efficient control of gene expression in the hematopoietic system using a single Tet-on inducible lentiviral vector. Mol Ther 13, 382-390 (2006).

101. Fuerer, C. \& Nusse, R. Lentiviral vectors to probe and manipulate the Wnt signaling pathway. PLoS One 5, e9370 (2010). 


\section{FIGURE 1}
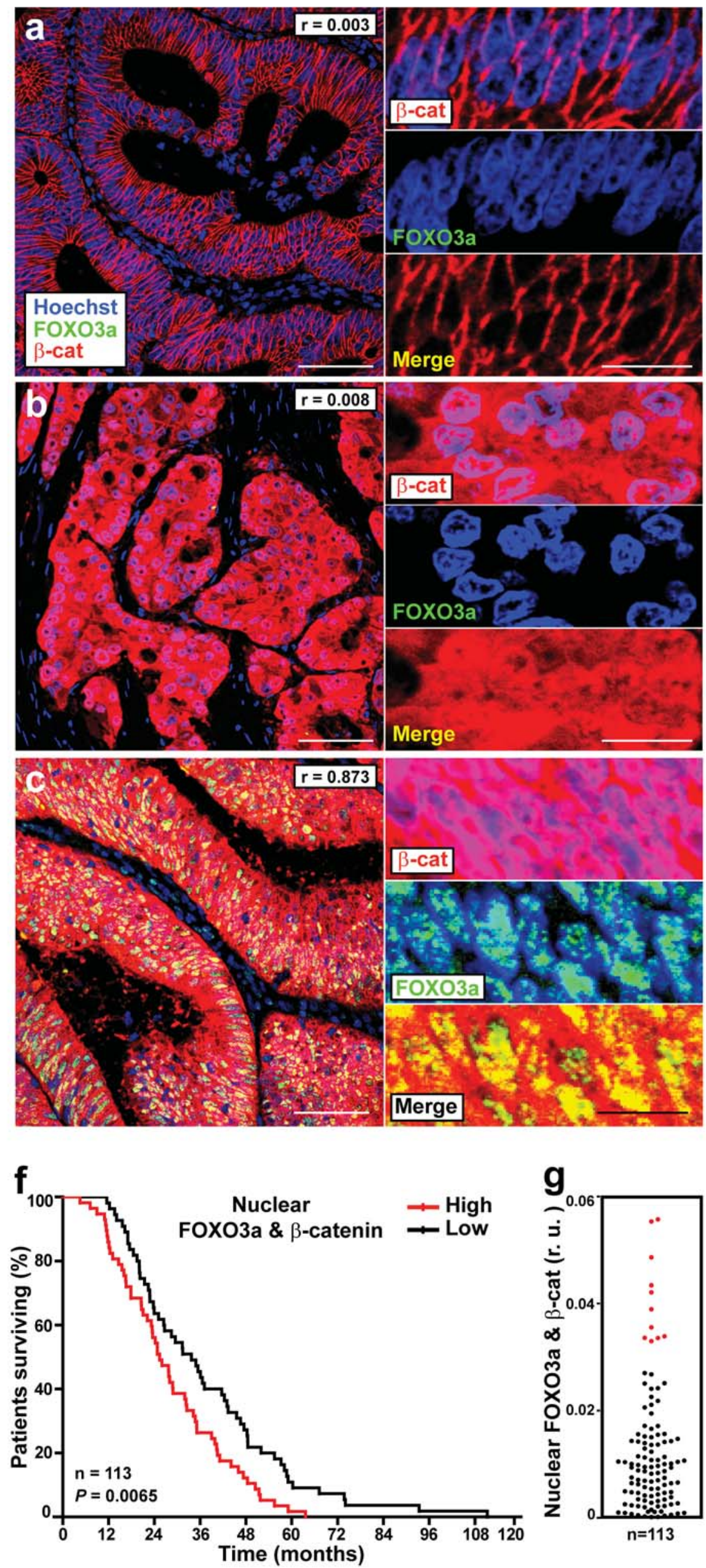
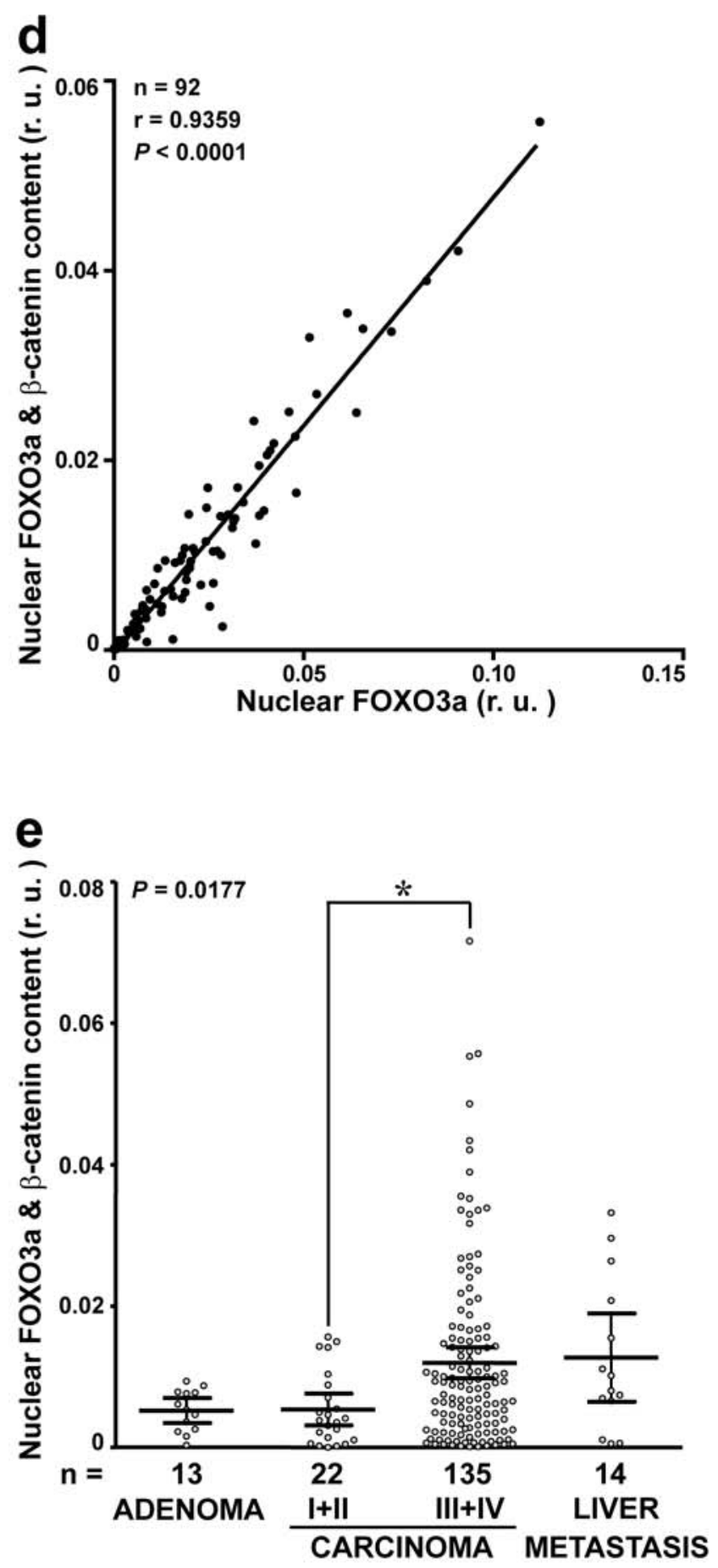

h

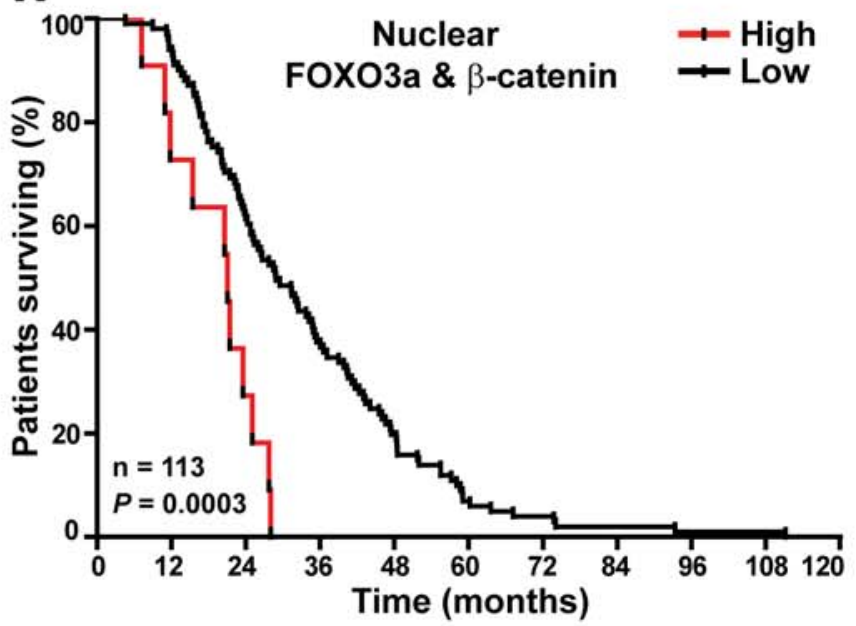




\section{FIGURE 2}
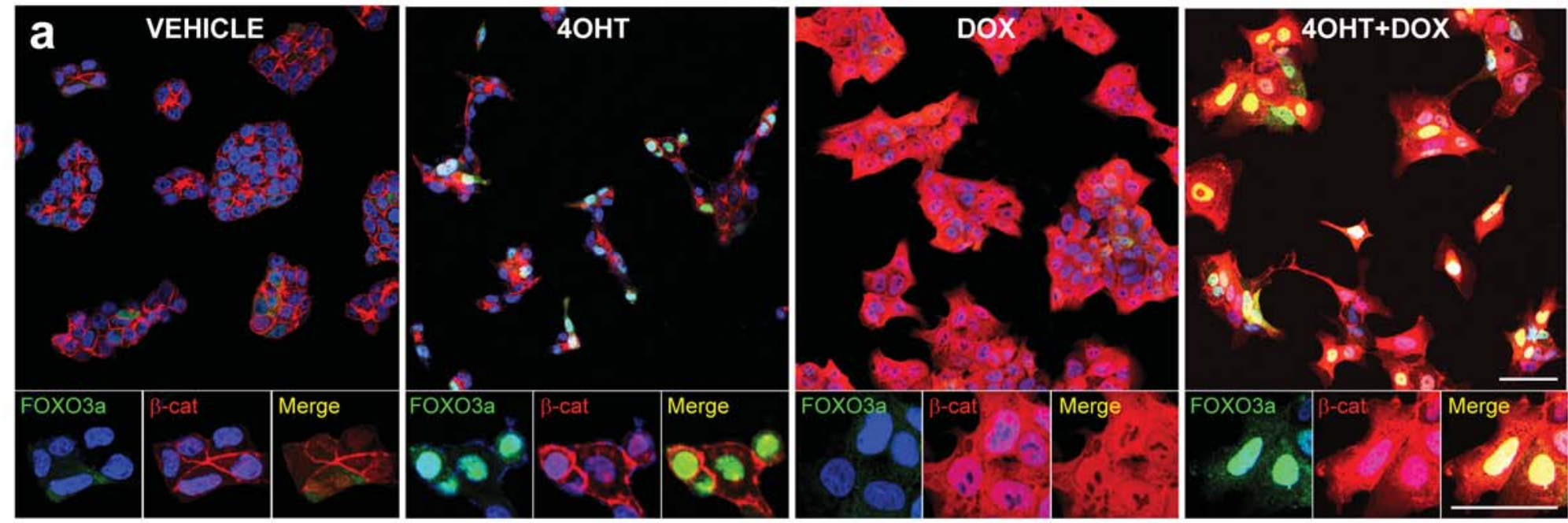

b

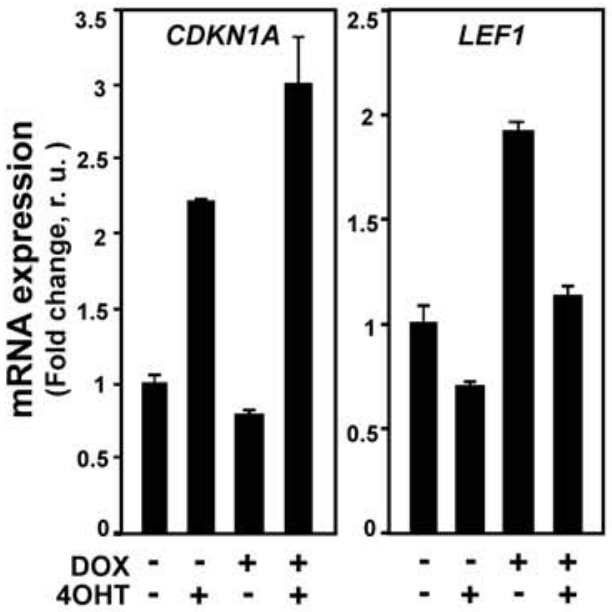

C

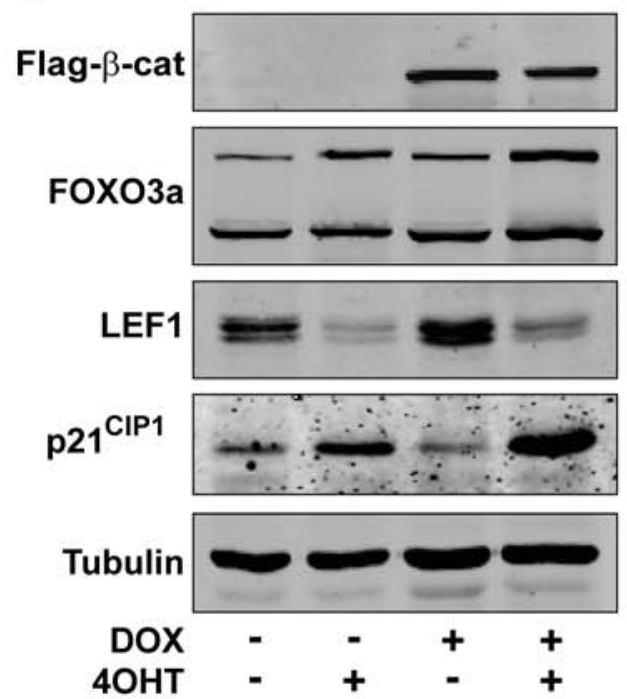

d

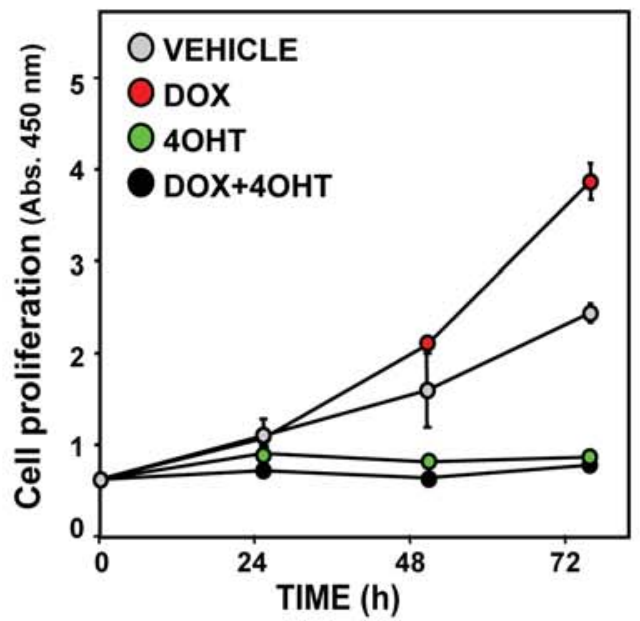

e

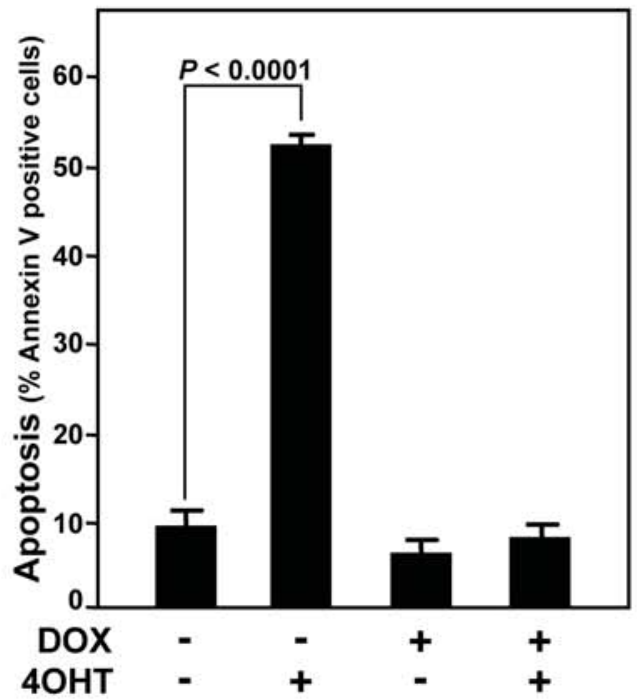

f

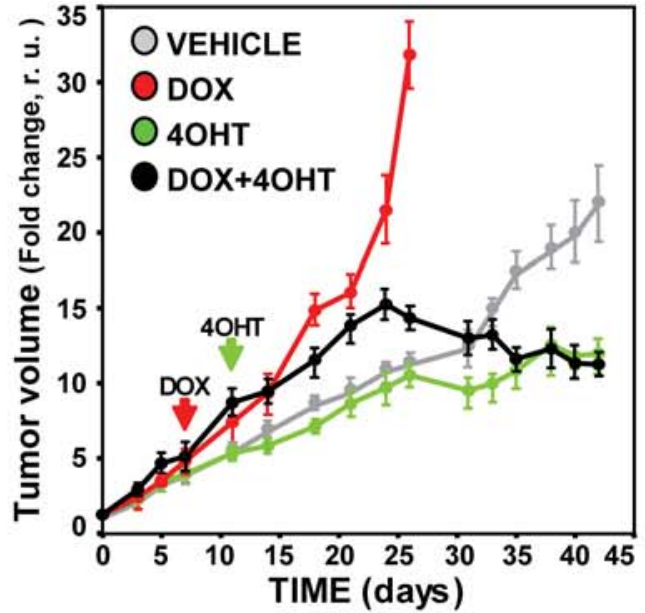

$9 \square$ egFP. $\square$ egFP+

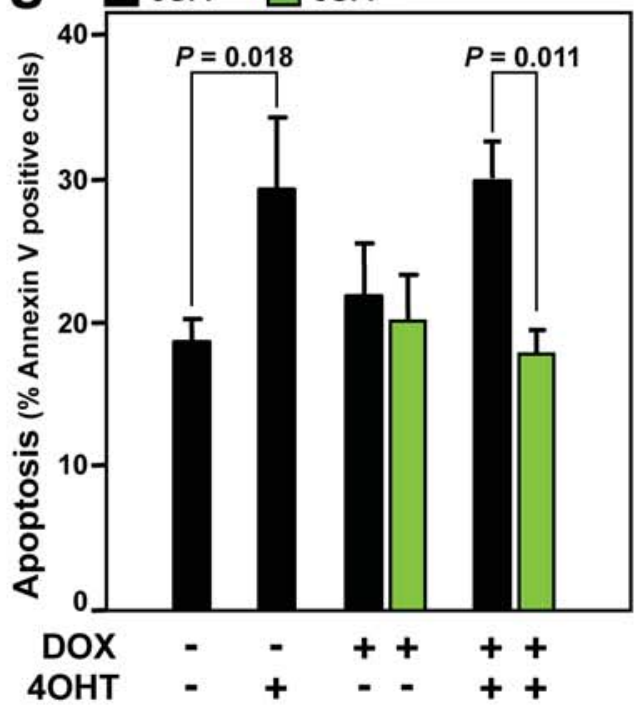


FIGURE 3
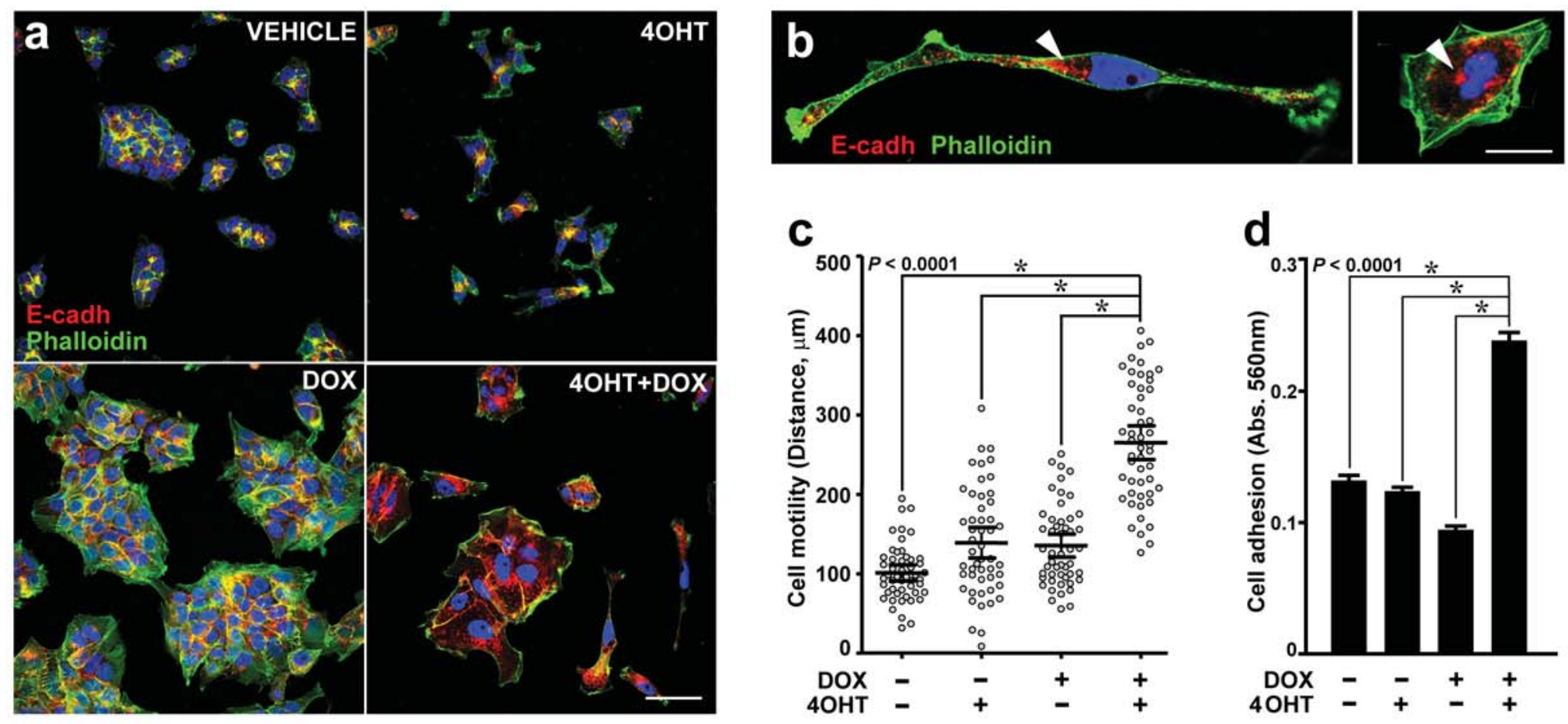

\begin{tabular}{|c|c|c|c|c|c|}
\cline { 3 - 6 } \multicolumn{1}{c|}{} & METASTASIS & \multicolumn{4}{|c|}{ DISSEMINATION SITE [Mice $(P$ value $)]$} \\
\cline { 3 - 6 } \multicolumn{1}{c|}{} & [Mice $(P$ value $)]$ & Liver & Lung & L.N. & Carc. \\
\hline VEHICLE & $2 / 9$ & $0 / 9$ & $0 / 9$ & $1 / 9$ & $2 / 9$ \\
\hline 4 OHT & $2 / 11(1)$ & $0 / 11(1)$ & $1 / 11(1)$ & $2 / 11(1)$ & $2 / 11(1)$ \\
\hline DOX & $1 / 9(1)$ & $0 / 9(1)$ & $1 / 9(1)$ & $1 / 9(1)$ & $0 / 9(1)$ \\
\hline 4 OHT+DOX & $9 / 11(0.022)$ & $0 / 11(1)$ & $5 / 11(0.038)$ & $5 / 11(0.157)$ & $8 / 11(0.07)$ \\
\hline
\end{tabular}
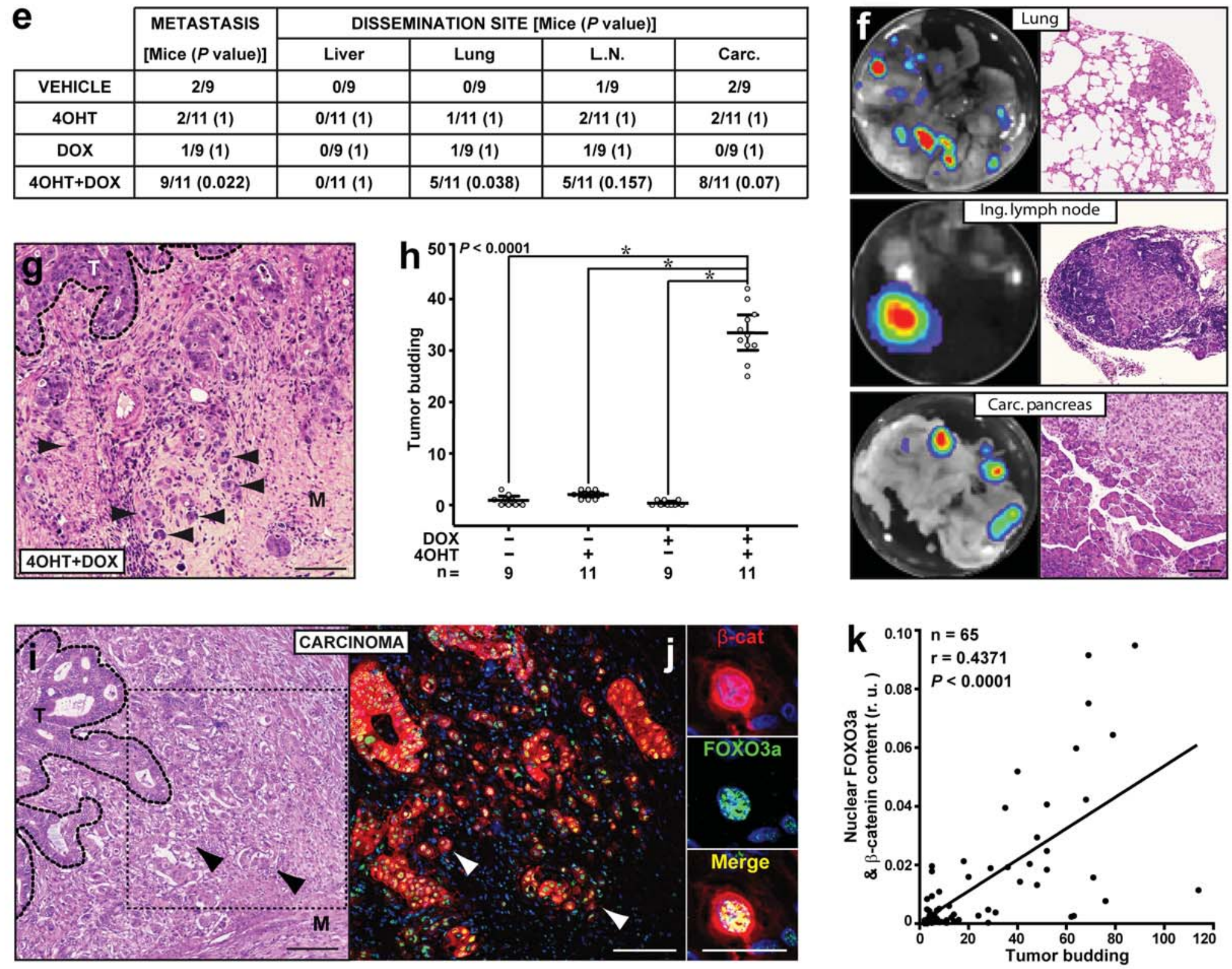
FIGURE 4

a

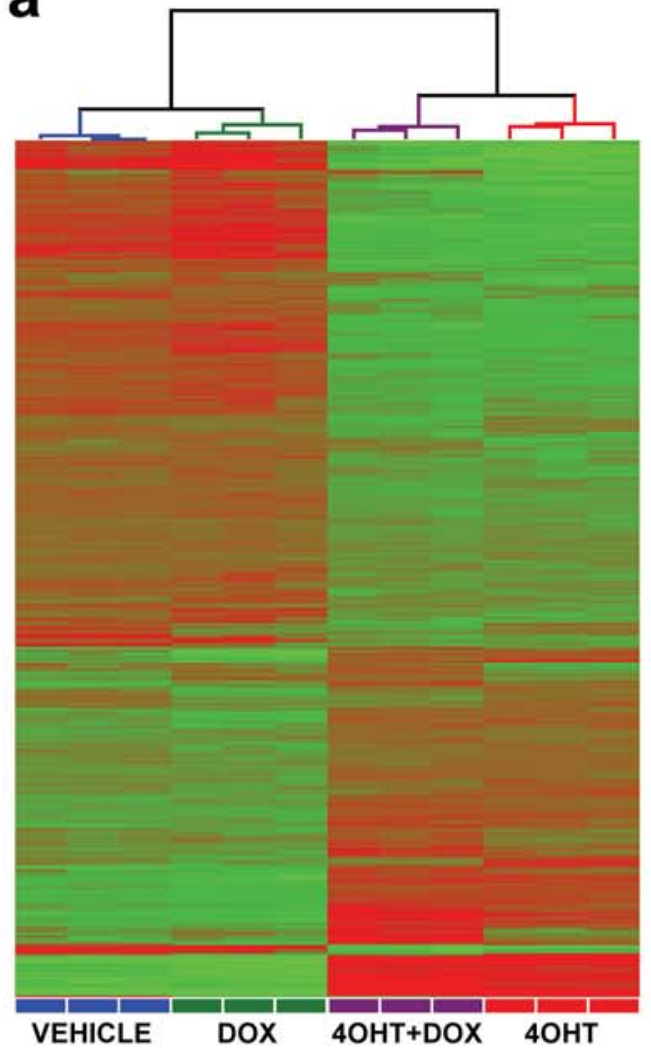

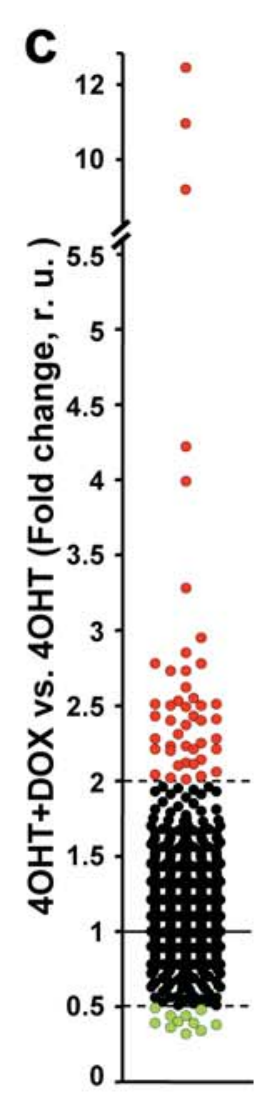

d
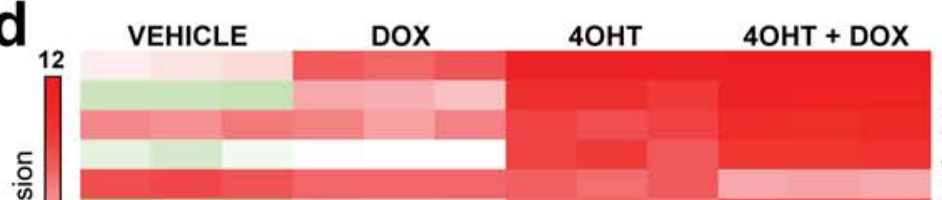

CAV1

CYR61

MBNL2

HBEGF

CDX2

CTGF

RICTOR

ITGB8

CLDN1

EDN1

EMP1

MTSS1L

SPINK

KIT

SLC2A3

\section{e}

\begin{tabular}{|c|c|c|c|c|c|}
\hline Gene Sym & HGNC Gene Name & vs. Ctrl. & vs. Ctrl. & $\begin{array}{l}\text { vs. Ctrl. } \\
\text { vs }\end{array}$ & vs. $40 \mathrm{OHT}$ \\
\hline$S L C 2 A 3$ & solute carrier family 2 , member 3 & 5.18 & 4.45 & 65.46 & 12.64 \\
\hline SPINK1 & serine peptidase inhibitor, Kazal type 1 & 7.82 & -1.99 & 19.54 & 2.50 \\
\hline EMP1 & epithelial membrane protein 1 & 13.06 & 2.61 & 28.72 & 2.20 \\
\hline EDN1 & endothelin 1 & 15.83 & 3.10 & 31.85 & 2.01 \\
\hline CTGF & connective tissue growth factor & 10.35 & 3.81 & 18.26 & 1.76 \\
\hline RICTOR & rapamycin-insensitive companion of Tor & 2.90 & n.s. & 4.81 & 1.66 \\
\hline MBNL2 & muscleblind-like 2 & 1.82 & n.s. & 2.76 & 1.52 \\
\hline CYR61 & cysteine-rich, angiogenic inducer, 61 & 18.87 & 3.59 & 27.63 & 1.46 \\
\hline HBEGF & heparin-binding EGF-like growth factor & 8.64 & n.s. & 11.81 & 1.37 \\
\hline CLDN1 & claudin 1 & 3.32 & 1.59 & 4.44 & 1.34 \\
\hline ITGB8 & integrin, beta 8 & 5.09 & n.s. & 6.76 & 1.33 \\
\hline CAV1 & caveolin 1 & 10.67 & 4.15 & 13,91 & 1.30 \\
\hline MTSS1L & metastasis suppressor 1 -like & -2.68 & n.s. & -3.51 & -1.31 \\
\hline KIT & kit oncogene & -5.08 & -2.13 & -7.28 & -1.43 \\
\hline$C D \times 2$ & caudal type homeobox 2 & -1.20 & -1.33 & -2.36 & -1.97 \\
\hline
\end{tabular}

b

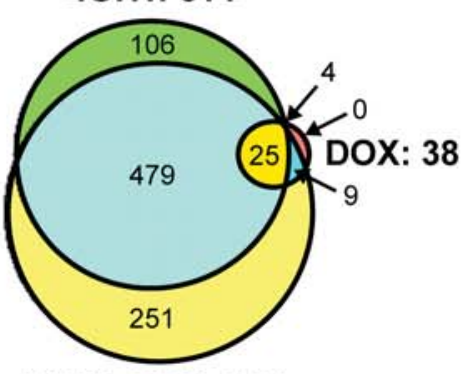

4OHT+DOX: 764
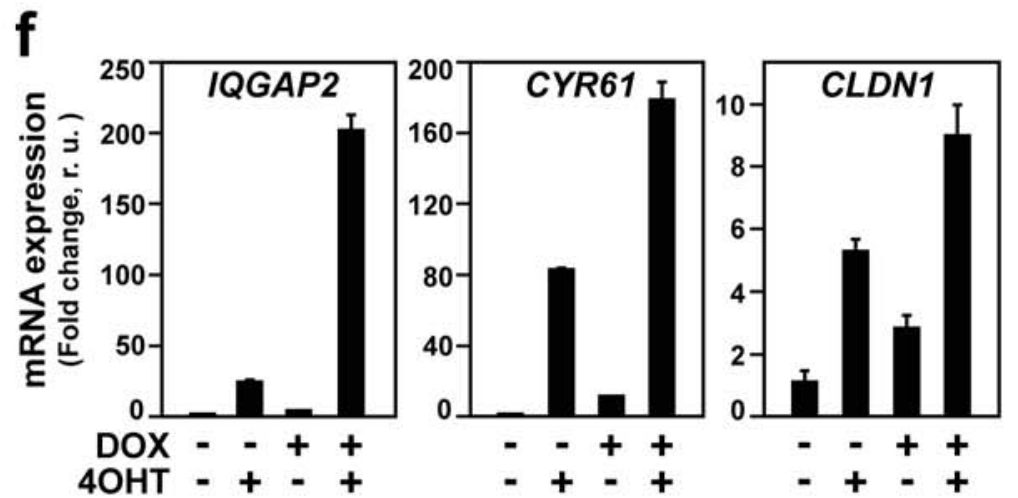

g

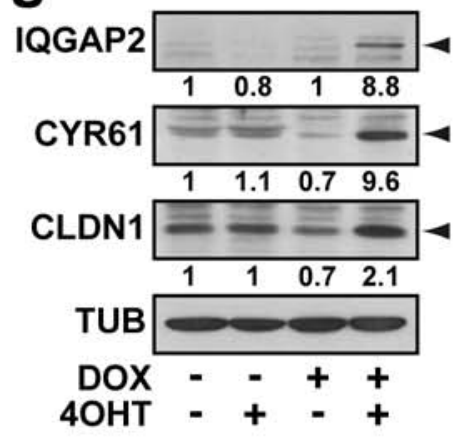

h

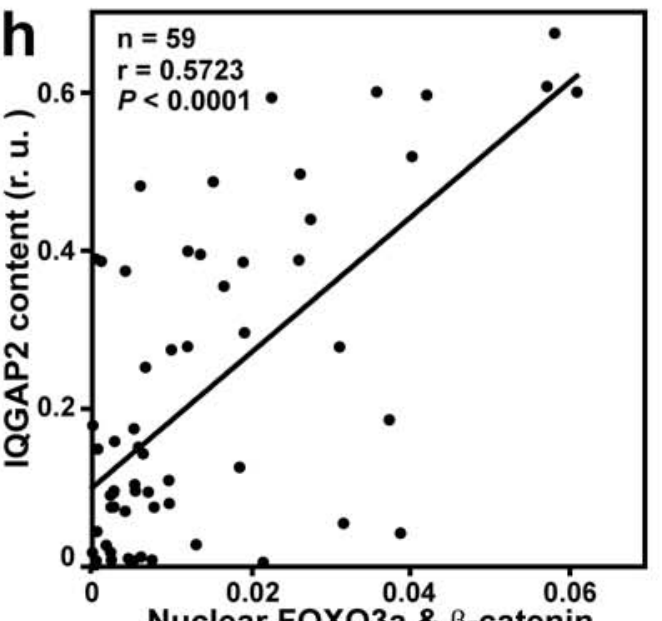

Nuclear FOXO3a \& $\beta$-catenin content (r. u. )

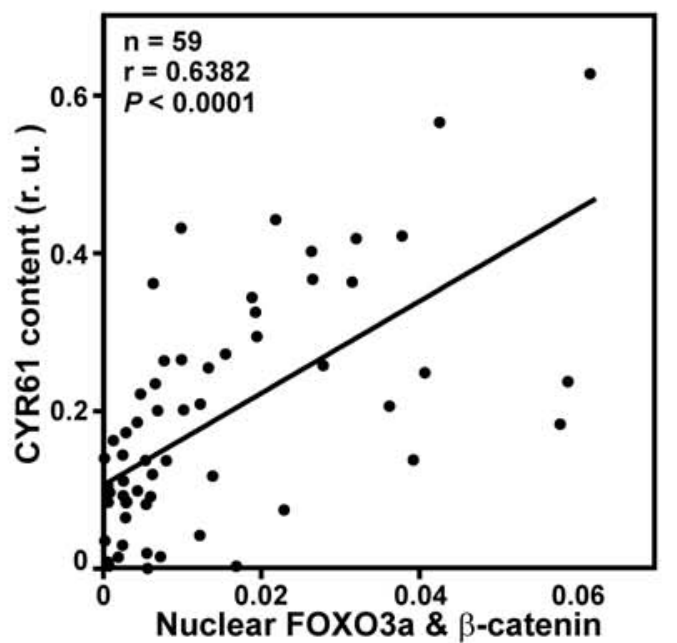

content (r. u. )

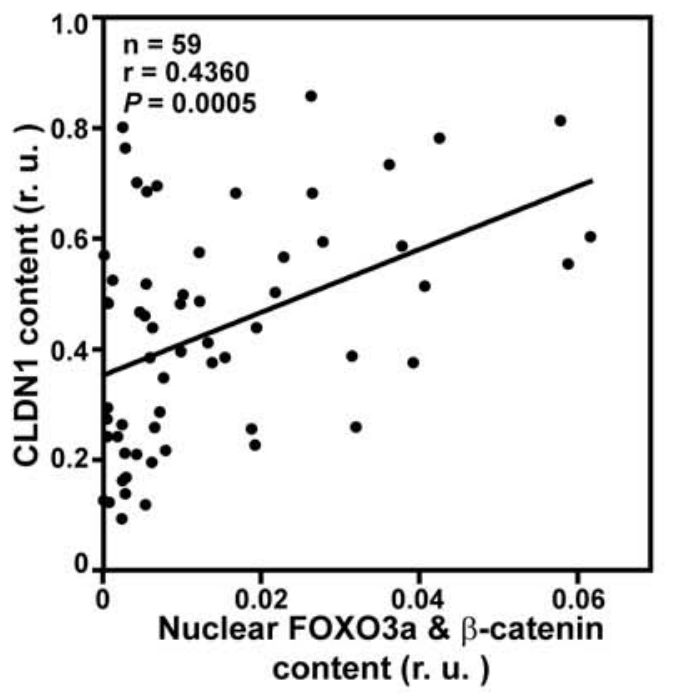




\section{FIGURE 5}

\section{a}

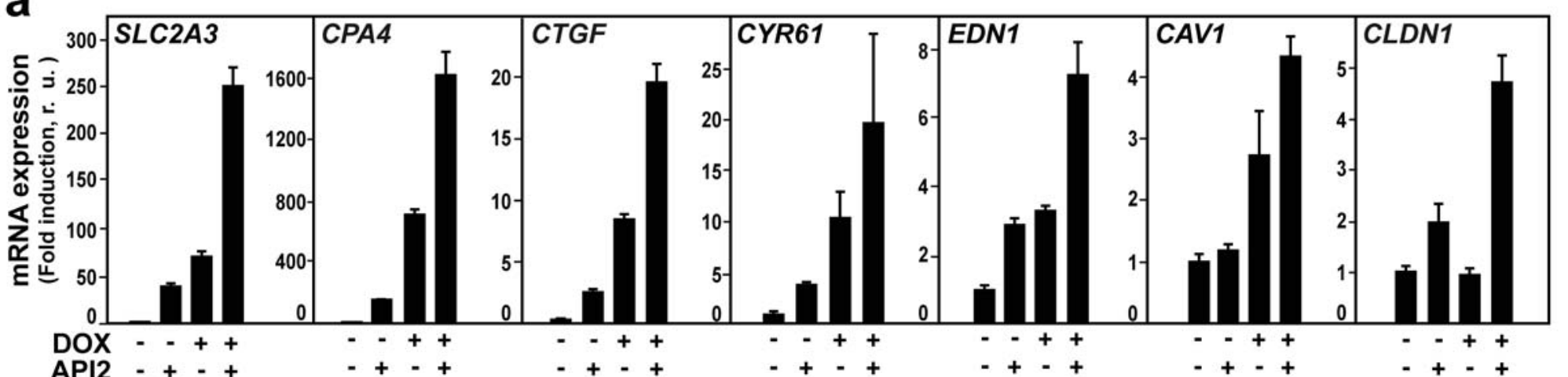

b

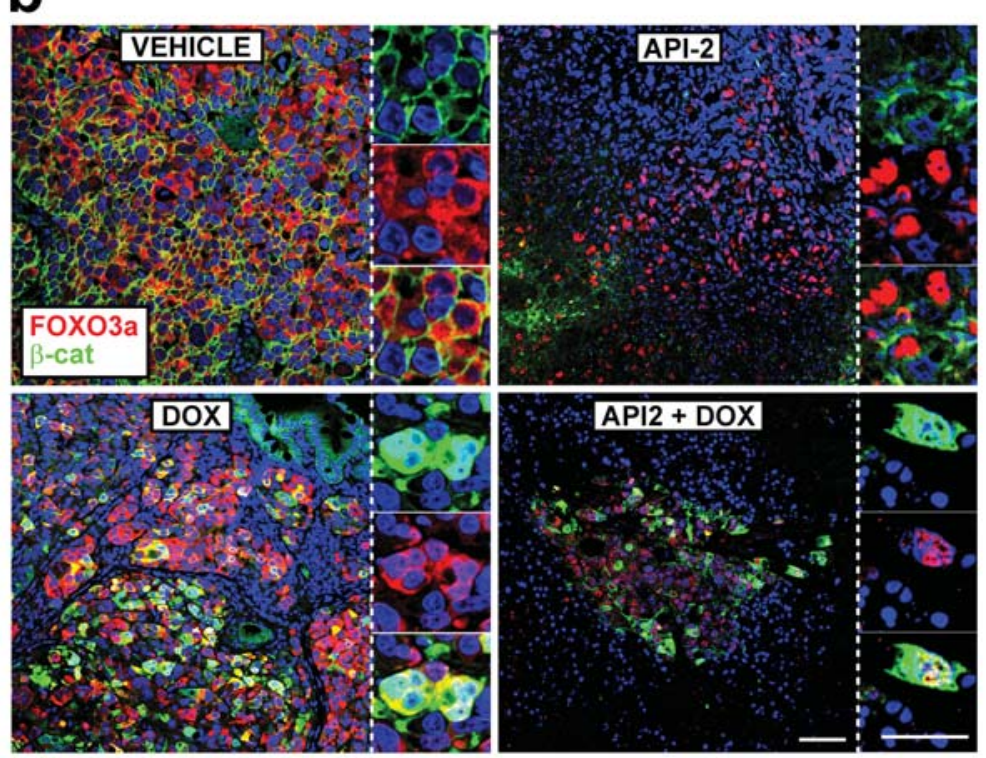

C

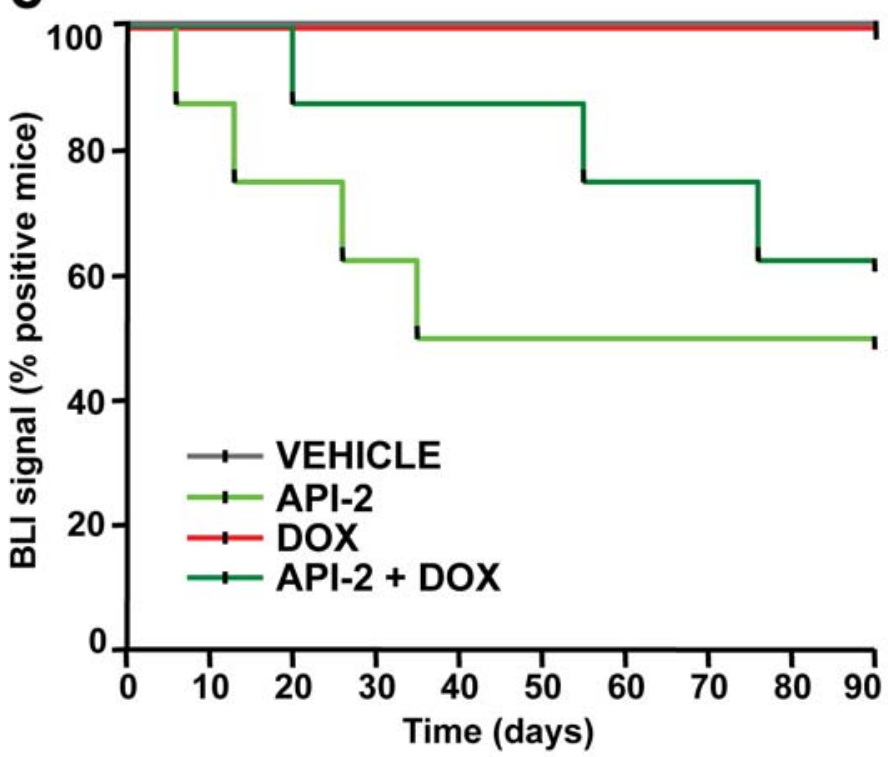

d

\begin{tabular}{|l|l}
\hline METASTASIS & DISSEMINATION SITE [Mice $(P$ value $)]$ \\
\hline
\end{tabular}

\begin{tabular}{|c|c|c|c|c|}
\hline [Mice $(P$ value $)]$ & Liver & Lung & L.N. & Carc. \\
\cline { 2 - 5 } & &
\end{tabular}

\begin{tabular}{|c|c|c|c|c|c|}
\hline VEHICLE & $2 / 9$ & $0 / 9$ & $0 / 9$ & $1 / 9$ & L.N. \\
\hline API-2 & $2 / 8(1)$ & $0 / 8(1)$ & $1 / 8(0.47)$ & $1 / 8(1)$ & $2 / 8(1)$ \\
\hline DOX & $1 / 9(1)$ & $0 / 9(1)$ & $1 / 9(1)$ & $1 / 9(1)$ & $0 / 9(1)$ \\
\hline API-2+DOX & $7 / 8(0.015)$ & $2 / 8(0.206)$ & $3 / 8(0.082)$ & $2 / 8(0.576)$ & $5 / 8(0.15)$ \\
\hline
\end{tabular}
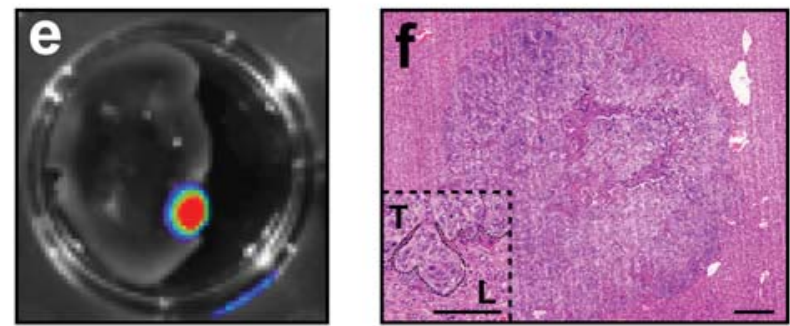

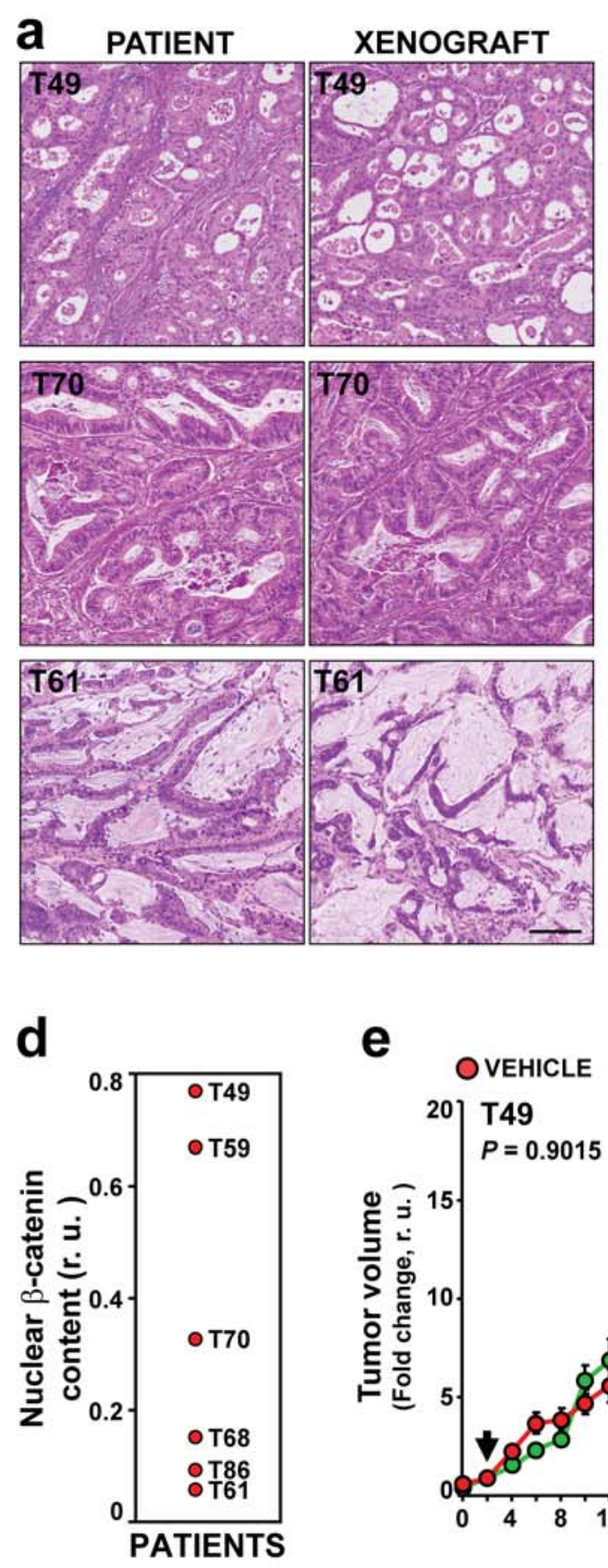

e

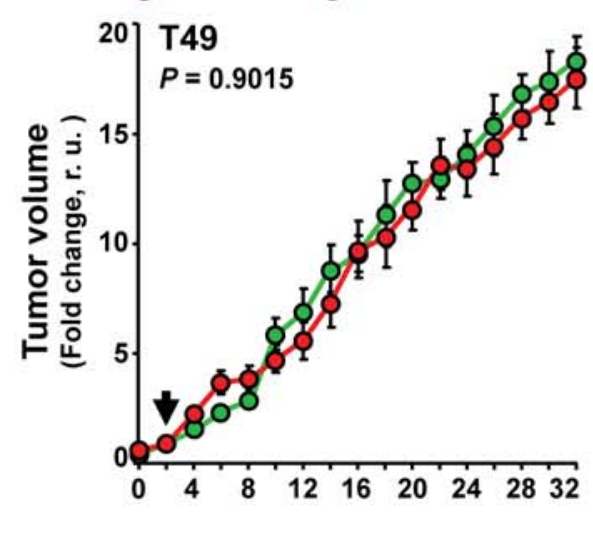

$f$
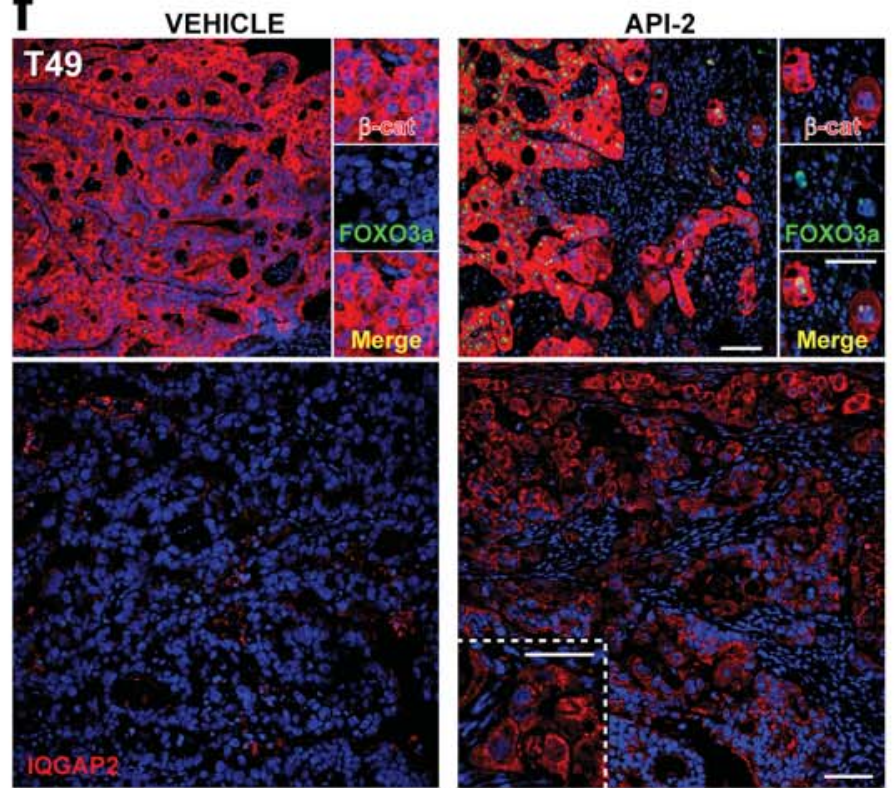

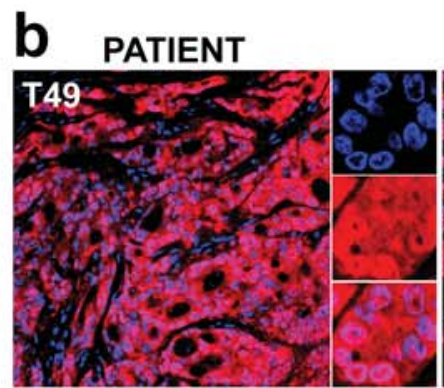

XENOGRAFT
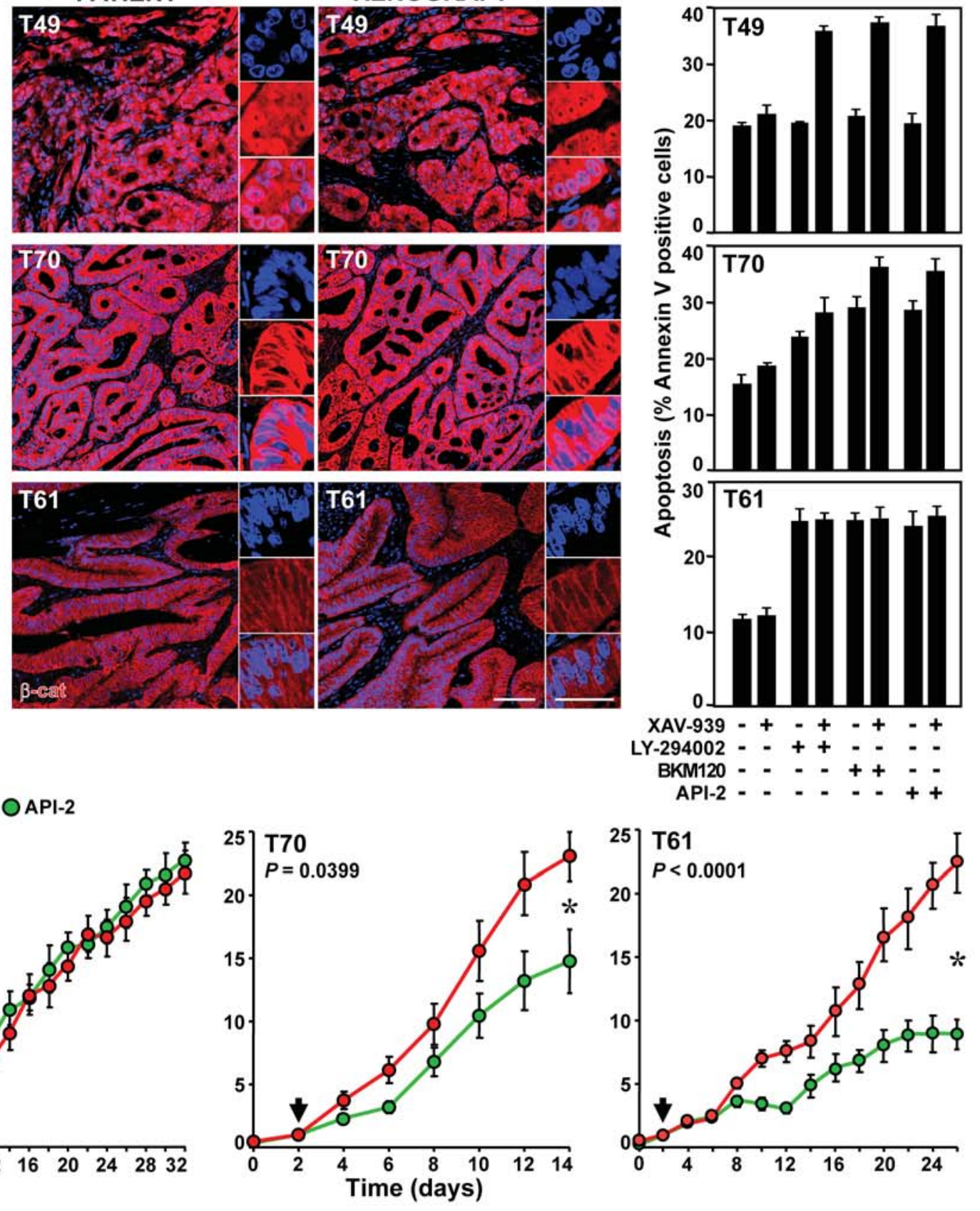

g

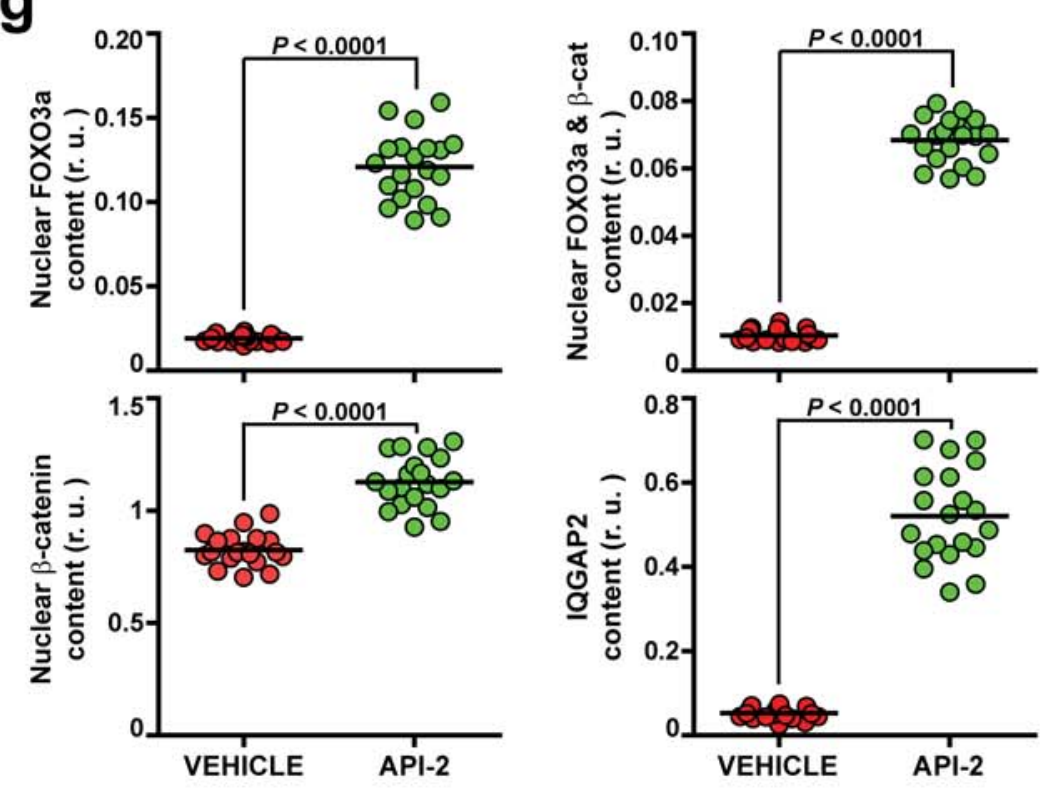

C
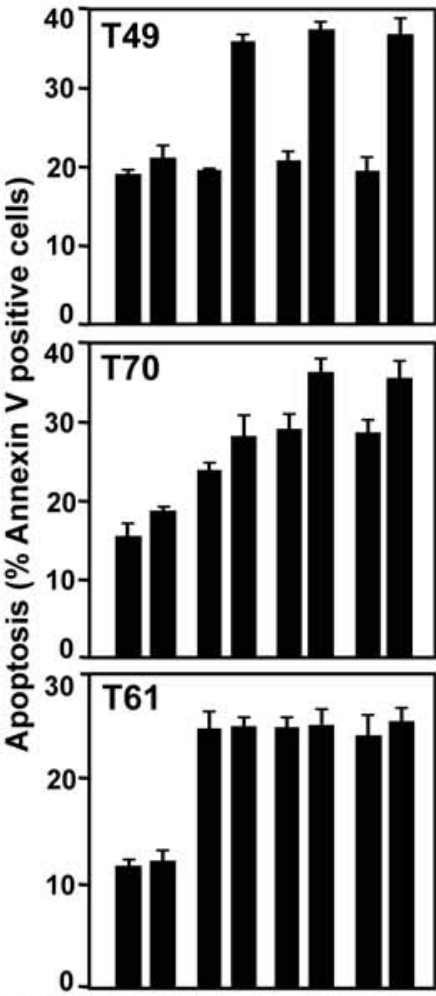

XAV-939 - + - + + - +

LY-294002 - - + + - - -

BKM120 - - - ++-

$\mathrm{API}-2$ - - - -++ 